\title{
Review
}

\section{Recent knowledge and innovations related to hexofuranosides: structure, synthesis and applications}

\author{
Pauline Peltier, Ronan Euzen, Richard Daniellou, ${ }^{*}$ Caroline Nugier-Chauvin* \\ and Vincent Ferrières*
}

\author{
Ecole Nationale Supérieure de Chimie de Rennes, Organic and Supramolecular Chemistry, UMR CNRS 6226, \\ Avenue du Général Leclerc, F-35700 Rennes, France
}

Received 5 October 2007; received in revised form 8 February 2008; accepted 12 February 2008

Available online 19 February 2008

Presented at Eurocarb 14th Lübeck, Germany, September 2007

\begin{abstract}
Hexofuranosides are widely spread in nature, and notably in numerous pathogenic microorganisms. This particular fivemembered ring for hexosides leads to novel biological properties and, as usual in glycochemistry, to completely different reactivity and selectivity. Far from being exhaustive, this review will first focus on the structure of the oligosaccharidic part of hexofuranosyl conjugates found in natural sources. Original syntheses will then be presented, stressing more particularly on the development of chemical and chemo-enzymatic tools for the access to 1,2-trans or 1,2-cis linkages. Finally, innovative applications related to biological, chemical and physicochemical fields for both natural and synthetic hexofuranosyl compounds will be described.
\end{abstract}

(C) 2008 Elsevier Ltd. All rights reserved.

Keywords: Hexofuranose-containing conjugates; Structure; Glycosylation reactions; Applications

\section{Contents}

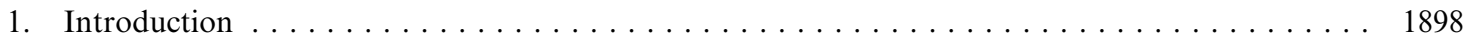

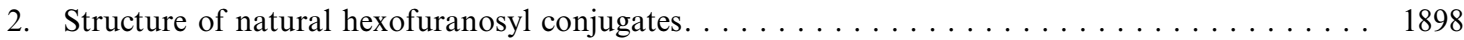

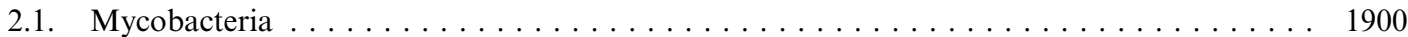

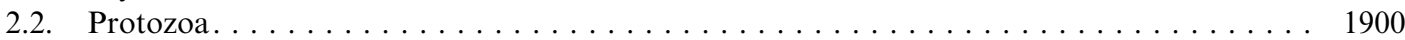

2.3. Fungi . . . . . . . . . . . . . . . . . . . . . . . . . . . . . . 1900

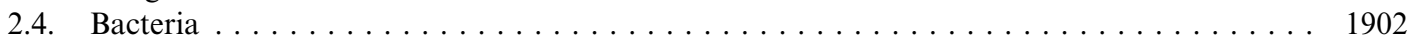

2.5. 1,2-cis Hexofuranosides in bacteria . . . . . . . . . . . . . . . . . . . . . . . . . 1903

2.6. Plants and other eukaryotic organisms . . . . . . . . . . . . . . . . . . . . . 1903

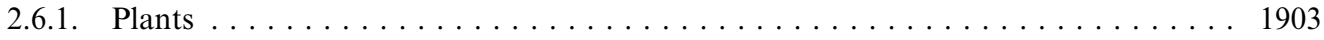

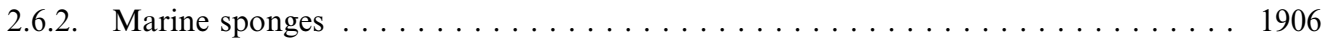

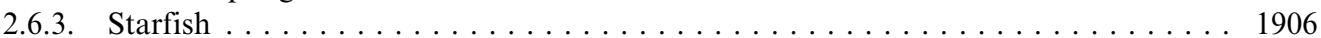

2.6.4. Archaebacteria . . . . . . . . . . . . . . . . . . . . . . . . . . . 1906

3. Recent advances in the synthesis of hexofuranosyl-containing oligosaccharides and conjugates . . 1907

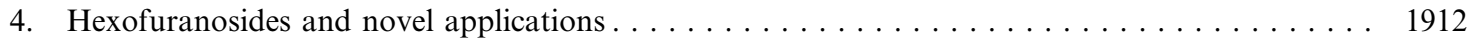

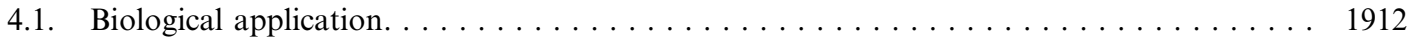

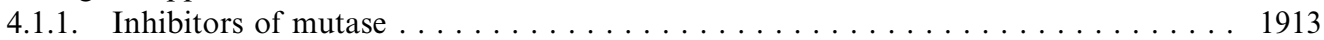

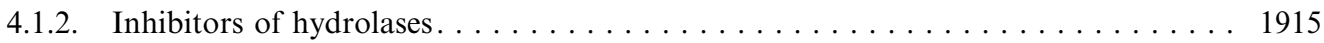

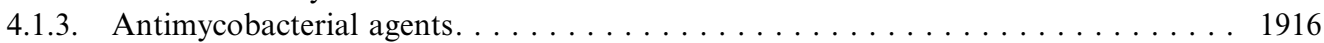

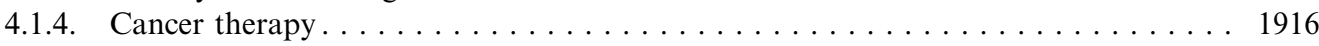

\footnotetext{
* Corresponding authors. Tel.: +33 223238 058; fax: +33 223238046 (V.F.); e-mail: vincent.ferrieres@ensc-rennes.fr
} 
4.2. Chemistry. . . . . . . . . . . . . . . . . . . . . . . . . . . . . . . 1916

4.3. Physicochemical applications . . . . . . . . . . . . . . . . . . . . . . . . . 1917

4.3.1. Amphiphiles and gelators . . . . . . . . . . . . . . . . . . . . . . . . . 1917

4.3.2. Dendrimers . . . . . . . . . . . . . . . . . . . . . . . . . . 1918

4.3.3. New biopolymers . . . . . . . . . . . . . . . . . . . . . . . . . . . . . . . . . 1918

Acknowledgements . . . . . . . . . . . . . . . . . . . . . . . . . . . . . . . . . . . . . 1919

References . . . . . . . . . . . . . . . . . . . . . . . . . . . . . . . . . . . . . . . . 1919

\section{Introduction}

Glycoconjugates are known to play important roles in numerous biological events. ${ }^{1}$ Most of the time, monosaccharide constituents are found in the hexopyranosyl form. During the last two decades, biomolecules involving hexofuranosyl constituents have attracted interest due to (i) their presence in various micro-organisms, even pathogenic ones, and (ii) their absence in mammals. Thus, these glycofuranosyl conjugates, as well as their analogues or derivatives, are promising candidates for new drugs. ${ }^{2}$ The detailed mechanisms of their biosynthesis and their metabolism have not yet been completely elucidated. In addition to classical hydrolases ${ }^{3}$ and transferases, ${ }^{4,5}$ the involvement of mutases ${ }^{6,7}$ which catalyze the interconversion between nucleotide pyranosyl and furanosyl sugars has been described. However, to our knowledge, few of these enzymes have been isolated and studied, except those related to the galactofuranosyl framework. For instance, there is no description in the literature of a gluco-, manno-, fucofuranosidase or transferase or mutase, even if related hexofuranosides have already been discovered in natural sources.

From a chemical point of view, hexoses exhibit significant differences depending on whether they are present as pyranosides or as furanosides. Indeed, it is well known that hexopyranosides are thermodynamically more favoured than their furanoside counterparts, notably because steric interactions are minimized in sixmembered rings. ${ }^{8}$ Moreover, stereoelectronic effects tend to stabilize electron-withdrawing aglycons with an axial orientation (Fig. 1). It results from this important parameter that $\alpha$-D-pyranosides having a ${ }^{4} C_{1}$ conformation are generally more stable than the corresponding equatorial $\beta$-anomers. Considering now the flexibility of furanosides, anomeric effects are not able to favour $\alpha$ - more than $\beta$-hexofuranosides since expression of

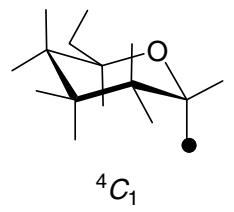

$\alpha-\mathrm{D}-$ pyrano

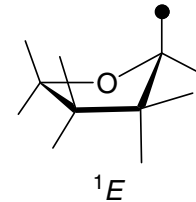

$\beta$-D-furano

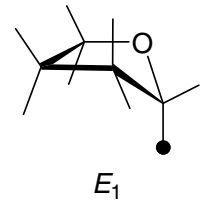

$\alpha$-D-furano
Figure 1. Conformations stabilized by anomeric effects. these electronic effects is possible in both cases. Consequently, orbital overlapping in furanosides cannot be as efficient as in pyranosides and could not explain alone the greater stability of one furanoside over its anomeric counterpart. Nevertheless, it was established from studies of nucleosides that equilibrium between north-type and south-type conformations is tightly dependent on anomeric and/or gauche effects involving O-2 or O-3. ${ }^{9-11}$

Furthermore, an apparent conformation of furanosides is mainly an average of all conformations encountered on a pseudo-rotational way generally involving envelope to twist interconversions. ${ }^{2,12-15}$ Finally, this could explain why protecting group manipulations in hexofuranosides seem to be slightly restricted in comparison with strategies frequently used with pyranosides (regioselective acylations and etherification, selective opening of benzylidene groups, etc.).

From these general considerations, the purpose of this review is not to be exhaustive but more particularly to focus on (i) the main biological sources of hexofuranosides and their structures, (ii) some recent advances in the field of their chemical and/or chemoenzymatic synthesis and (iii) their potential use in various domains such as in biology, chemistry and physicochemistry.

\section{Structure of natural hexofuranosyl conjugates}

Polysaccharides composed of hexofuranosyl residues are important constituents of glycoconjugates from many bacteria, ${ }^{16,17}$ protozoa, ${ }^{18}$ fungi, ${ }^{19}$ plants $^{20}$ and archaebacteria. ${ }^{21}$ Hexofuranosyl constituents have also been identified in glycopeptides, glycolipids as well as nucleotide sugars. The structure of the latters will be presented in the enzymatic synthesis part of this review.

D-Galactose is by far the most widespread hexose in the furanose form in naturally occurring polysaccharides, and the most impressive examples of these glycans are encountered in mycobacteria. Moreover, glycoconjugate structures including the D-Gal $f$ unit in the 1,2trans anomeric configuration have been found in many microorganisms, not necessarily pathogenic, as well as in some pluricellular organisms. A few of them are Oglycosidically-linked to another D-Gal $f$ unit by $(1 \rightarrow 2)$, $(1 \rightarrow 3),(1 \rightarrow 5)$ or $(1 \rightarrow 6)$ linkages, and others are at- 
tached to glycopyranoside entities such as D-Man $p$, DGlc $p$, D-Glc $p$ NAc, D-Gal $p$, D-Gal $p$ NAc, D-Fru $p$ and L-Rhap. Some examples are presented in Table 1, with indication of the microorganism in which these glycoconjugates are present. Importantly, Gal $f$ has been shown to be present in numerous structures considered

Table 1. Natural $\beta$-D-Galf-containing oligosaccharidic structures

\begin{tabular}{|c|c|c|c|}
\hline Glycosidic linkage & $\operatorname{Organism}(\mathrm{s})^{\mathrm{a}}$ & Glycosidic linkage & Organism(s) \\
\hline \multirow{3}{*}{$(1 \rightarrow 2)$-D-Galf } & Penicillium $^{22}$ & $(1 \rightarrow 2)$-D-Manp & Bionectria $^{24}$ \\
\hline & Talaromyces ${ }^{23,24}$ & & Byssochlamys $^{24,26}$ \\
\hline & Trypanosoma cruzi ${ }^{25}$ & & Cryphonectria parasitica ${ }^{27}$ \\
\hline \multirow[t]{6}{*}{$(1 \rightarrow 3)$-D-Galf $f$} & Aspergillus $^{24,31}$ & & Hypocrea ${ }^{24,28}$ \\
\hline & Chaetosartory $a^{24}$ & & Neurospora ${ }^{24,29,30}$ \\
\hline & Penicillium $^{22}$ & & Paecilomyces ${ }^{26}$ \\
\hline & Renibacterium & & Trichoderma ${ }^{28}$ \\
\hline & salmoninarum $^{32}$ & $(1 \rightarrow 3)$-D-Manp & Aspergillus $^{33}$ \\
\hline & Talaromyces $^{23,24}$ & & Trypanosoma cruzi $i^{18,34}$ \\
\hline \multirow[t]{23}{*}{$(1 \rightarrow 5)-\mathrm{D}-\mathrm{Gal} f$} & Actinobacillus & & Leishmania $^{35}$ \\
\hline & pleuropneumoniae $^{36}$ & & \\
\hline & Arachniotus $^{24}$ & $(1 \rightarrow 6)-\mathrm{D}-\mathrm{Man} p$ & Aspergillus $^{33,37,40,49}$ \\
\hline & Aspergillus $^{24,33,37-40}$ & & Epidermophyton ${ }^{30}$ \\
\hline & Bionectria $^{24}$ & & Microsporum $^{30}$ \\
\hline & Byssochlamys ${ }^{24,26}$ & & Paraccidioides \\
\hline & Chaetosartorya ${ }^{24}$ & & brasiliensis $^{50}$ \\
\hline & Cryphonectria & & Rocella decipens ${ }^{51}$ \\
\hline & parasitica $^{27}$ & & Trichophyton $^{30}$ \\
\hline & Discula $^{30}$ & $(1 \rightarrow 3)$-D-Glcp & Steptococcus thermophilus \\
\hline & Eupenicillium $^{24,41}$ & 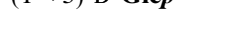 & Sfi $39^{52}$ \\
\hline & Gymanascella & $(1 \rightarrow 6)$-D-Glcp & Escherichia coli $\mathrm{K}-12^{53}$ \\
\hline & Hypocrea $^{24,28}$ & $(1 \rightarrow 4)$-D-GlcpNAc & Trypanosoma cruzi $i^{25}$ \\
\hline & Mycobacterium $^{16,42-45}$ & $(1 \rightarrow 3)$-D-Galp & Agelas sp. ${ }^{54}$ \\
\hline & Nectria $^{46}$ & & Agelas longissima ${ }^{55}$ \\
\hline & Neosatorya $a^{24,39}$ & & Bacteroides cellulovens ${ }^{56}$ \\
\hline & Paecilomyces $^{26}$ & & Fibrobacter succinogenes $\mathbf{S 8 5}^{57}$ \\
\hline & Penicillium $^{22,47}$ & & \\
\hline & Rocella decipiens & $(1 \rightarrow 3)$-D-GalpNAc & Bacteroides fragilis $9343^{58}$ \\
\hline & Sesquicillium $^{46}$ & & Hafnia alvei ${ }^{59}$ \\
\hline & Talaromyces $^{23,24,48}$ & & Escherichia coli $\mathrm{O} 164^{60}$ \\
\hline & Trichoderma ${ }^{28}$ & & Shygella dysenteriae type $3^{60}$ \\
\hline & & $(1 \rightarrow 4)$-L-Rhap & Mycobacterium $^{16,42-45}$ \\
\hline \multirow[t]{24}{*}{$(1 \rightarrow 6)$-D-Galf $f$} & Arachniotus $^{24}$ & & Pleisiomonas \\
\hline & Aspergillus $^{30,39}$ & & shigelloides $^{61}$ \\
\hline & Bionectria $^{24}$ & $(1 \rightarrow 3)$-D-Frup & Rahnella aquatilis $^{68}$ \\
\hline & Byssochlamys ${ }^{24,26}$ & & \\
\hline & Calonectria ${ }^{24,62}$ & & \\
\hline & Cryphonectria & & \\
\hline & parasitica $^{27}$ & & \\
\hline & Cyclindocladium $^{62}$ & & \\
\hline & Discula ${ }^{30}$ & & \\
\hline & Fusarium $^{63,64}$ & & \\
\hline & Gibberella $^{24,64}$ & & \\
\hline & Gymanascella & & \\
\hline & Hypocrea $^{24,28}$ & & \\
\hline & Mycobacterium $^{16,42-45}$ & & \\
\hline & Myrothecium $^{65}$ & & \\
\hline & Nectria $^{64}$ & & \\
\hline & Neosatorya ${ }^{24,39}$ & & \\
\hline & Paecilomyces $^{26}$ & & \\
\hline & Penicillium $^{22,47}$ & & \\
\hline & Renibacterium & & \\
\hline & salmoninarum $^{66}$ & & \\
\hline & Sesquicillium $^{46}$ & & \\
\hline & Talaromyces ${ }^{23,24,67}$ & & \\
\hline & Trichoderma ${ }^{28}$ & & \\
\hline
\end{tabular}

\footnotetext{
${ }^{a}$ Microorganisms, whose pathogenicity has been clearly demonstrated, are labelled in bold face.
} 
to be essential for virulence in many pathogenic organisms. In addition to Gal $f$, Fruf $f$ is one of the most common furanosidic monosaccharide found in nature but in less abundant varieties of polysaccharide structures. Others besides these sugars could be encountered more scarcely in bacteria or plants, for example, D-Glcf, DFuc $f$ or even D-Man $f$.

\subsection{Mycobacteria}

One notable example is that of Mycobacterium tuberculosis, which despite several decades of successful chemotherapeutic treatment has reemerged through multidrug resistance to become a major cause of mortality, with an annual rate of approximately 3 millions over the world. ${ }^{69}$ The cell wall complex in this species is largely composed of two polysaccharides, a lipoarabinomannan (LAM) and an arabinogalactan (AG), in which all the galactose and the arabinose residues are present as five-membered rings. ${ }^{16,70}$ The AG portion of mycobacteria comprises a linear chain of approximately 30 alternating $\beta-(1 \rightarrow 5)$ - and $\beta-(1 \rightarrow 6)$-linked $\mathrm{D}-\mathrm{Gal} f$ residues (Fig. 2). Each galactan chain is believed to contain 2 or 3 arabinan chains and the linkage position is to $\mathrm{O}-$ 5 of the Galf unit. The mycobacterial cell wall core, consisting of an outer lipid (mycolic acid) layer attached to peptidoglycan via the AG, is unique to mycobacteria and other Actinomycetes. Therefore, the inhibition of the pathways leading to its formation is particularly attractive from the perspective of drug development. ${ }^{71}$ Indeed, inhibition of the enzymes that assemble these polyfuranosides prevents the proliferation of mycobacteria, including the causative agent of tuberculosis, M. tuberculosis. ${ }^{72,73}$ These findings, and the fact that such furanosyl residues are not found in mammals, support the research on these enzymes as important targets for the design of new antituberculosis drugs.

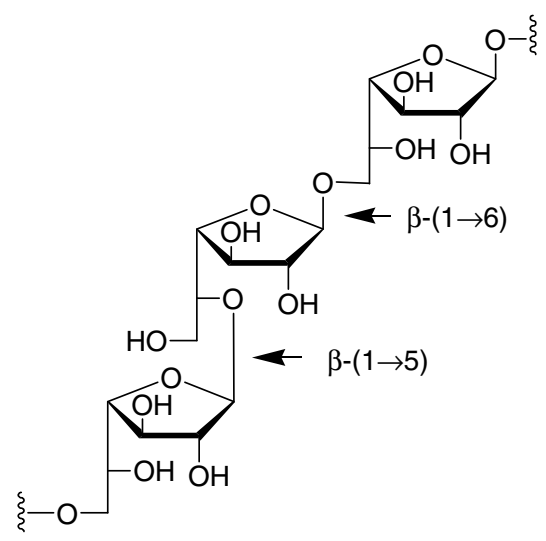

Figure 2. Galactan fragment of the arabinogalactan from the mycobacterial cell wall.

\subsection{Protozoa}

The D-Gal $f$ residues are also present in the $\beta$-anomeric configuration in eukaryotic pathogens such as Trypanosoma cruzi and Leishmania major. Protozoan parasites of the genus Leishmania are the causative agents of leishmaniasis, which infects more than 10 million people worldwide through the sand-fly mediated transmission. The surface of the promastigote stage of Leishmania is coated with a variety of interrelated glycoconjugates including lipophosphoglycan (LPG), glycoinositol phospholipids (GIPLs), proteophosphoglycan (PPG) and glycosyl phosphatidylinositol (GPI)-anchored proteins. ${ }^{18,35,74-76}$ In some species of Leishmania, such as L. major, as well as in T. cruzi, the core of the abundant surface LPG is structurally related to that of the smaller GIPLs in containing Galf residues in a $\beta-G a l f-(1 \rightarrow 3)$ Man $p$ motif, suggesting a common biosynthetic pathway. Usually the LPG core hexasaccharide myo-inositol is substituted with an $\alpha$-D-glucosyl 1-phosphate as shown in Figure 3. It is worth mentioning that both glycolipid complexes LPG and GIPLs act as virulence factors involved in the recognition and attachment of host macrophages as well as in binding to the gut of the insect responsible for the transmission of Trypanosoma or Leishmania parasites in mammalian host during the disease process. ${ }^{75,77-81}$ Moreover, the presence of Galf units has been demonstrated in N-glycoproteins of some species of trypanosomatids such as Endotrypanum schaudinni, where asparagine-linked oligosaccharides have two peculiarities, the presence of Gal $f$ as well as ribose residues. $^{82}$

\subsection{Fungi}

Fungi are other microorganisms recognized as an increasing cause of infection (aspergilloses, systemic candidoses) especially in immunodeficient patients and in those treated with immunorepressive agents. It has been observed that during the growth of moulds, exopolysaccharides (EPS) with immunological properties are produced. Structural analysis of the EPS from Aspergillus and Penicillium species indicated the presence of a major core chain composed of $(1 \rightarrow 2)$ - and $(1 \rightarrow 6)$-linked $\alpha$-D-mannopyranosides, which contained side chains of around 4-10 units of $(1 \rightarrow 5)$-linked $\beta$-Dgalactofuranoside residues (Fig. 4). ${ }^{19}$ It is noteworthy that Gal $f$ units were shown to be immunodominant in the galactomannans produced by Aspergillus fumigatus. ${ }^{49,83-86}$ More recently, Barreto-Bergter and co-work$\mathrm{ers}^{31}$ demonstrated that immunodominant epitopes were present in the O-linked tetra- and hexasaccharides of the peptidogalactomannan portion of A. fumigatus mycelial cell wall and contained a $\beta$-Gal $f-(1 \rightarrow 5)-\beta$-Gal $f$ terminal group. Despite being the less abundant carbohydrate component of the A. fumigatus peptidogalactomannan, 


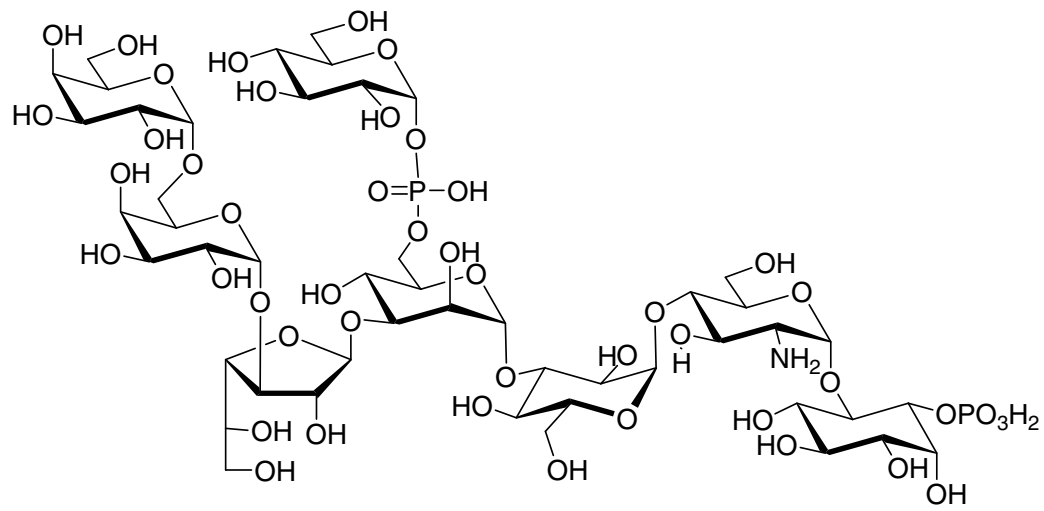

Figure 3. LPG core hexasaccharide myo-inositol fragment found on the surface of the Leishmania parasite.
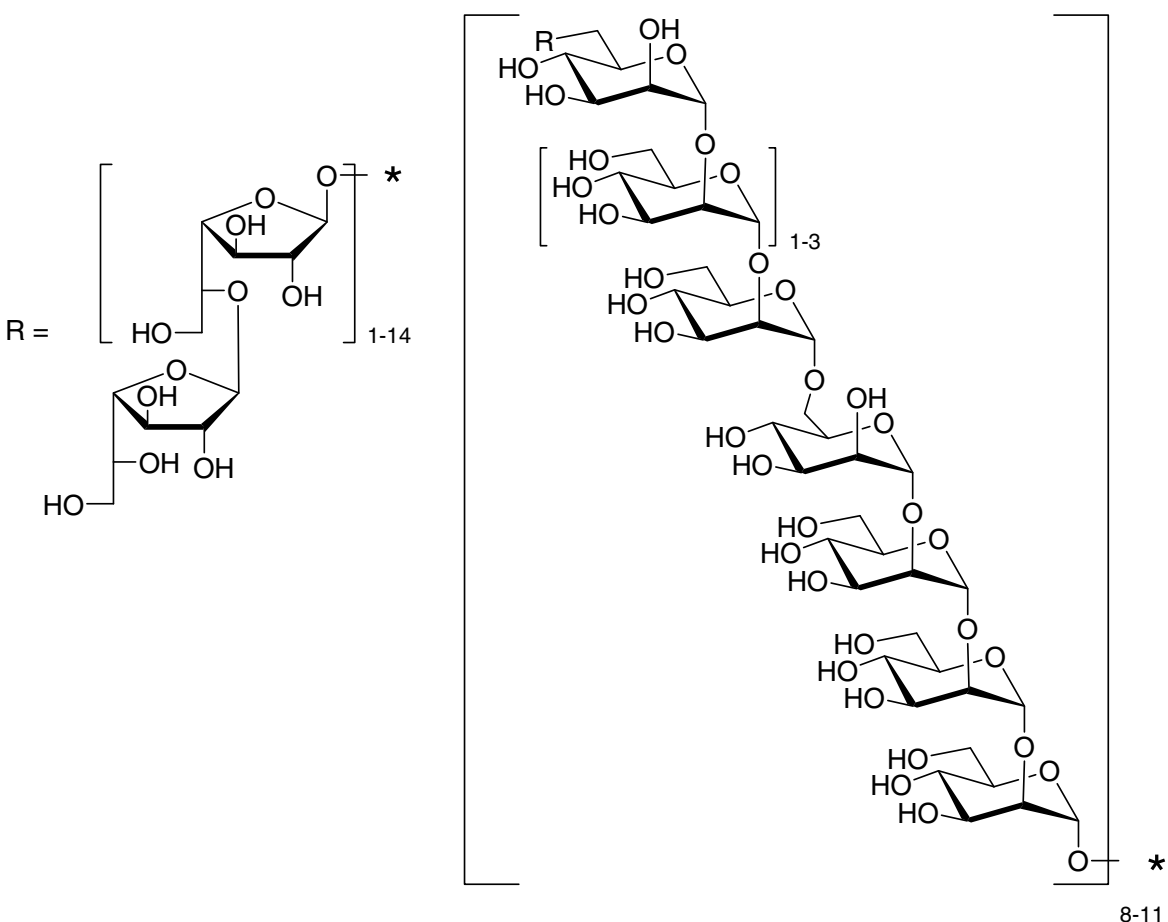

Figure 4. Galactomannan core structure of the EPS produced by Aspergillus and Penicillium species.

these O-linked oligosaccharides may account for a significant part of its antigenicity. At least, a polysaccharide isolated from another species, Aspergillus versicolor, appears to have a similar structure, except for the presence of phosphodiester groups. NMR data suggested that these groups were mainly present as bridges between C-1 of $\alpha-\mathrm{D}-\mathrm{Man} p$ and C-6 of 5-Osubstituted $\beta$-D-Gal $f$ units. ${ }^{87}$

More generally, the fungal cell wall is mainly built up of polysaccharides. Among them, the widely distributed $\beta$ - $(1 \rightarrow 3)$-glucan is a cell wall component of most medically important fungi, including $A$. fumigatus. However, there is no doubt that other polysaccharides appearing in minor amounts could be characteristic of a limited group of fungi. ${ }^{46,47}$ For instance, a novel galactofuranan has been purified from fifteen species of Eupenicillium. ${ }^{48}$ Moreover, in Talaromyces helicus, a heteropolysaccharide rich in $(1 \rightarrow 2)$ - and $(1 \rightarrow 5)$-linked Gal $f$ units has been described ${ }^{88}$ In some of these species, the galactofuranosidic entity appeared to be the antigenic determinant. ${ }^{89}$ In a very recent study, the release of both $\beta$ $(1 \rightarrow 5)$-Gal $f$ antigens and $\beta$-( $1 \rightarrow 3)$-D-glucans has been studied as in vitro Aspergillus markers for the early diagnosis of invasive aspergillosis. ${ }^{90}$

Another noteworthy example of D-Galf-containing glycoconjugates found in fungi is a glycosylinositol phosphorylceramide isolated from Paracoccidioides brasiliensis, a mycopathogen endemic to rural areas of 


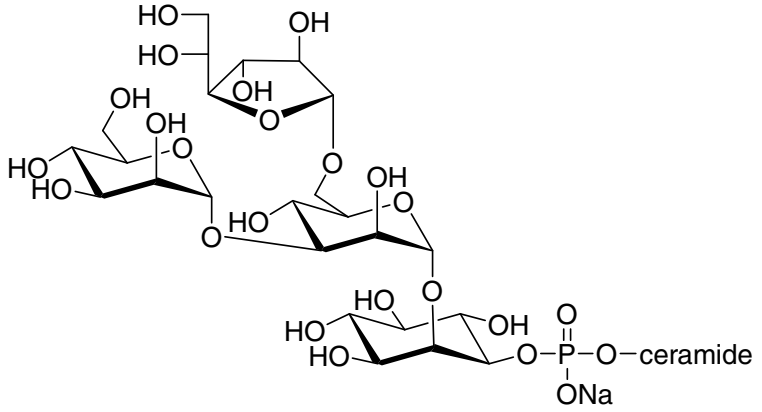

Figure 5. Glycosylinositol phosphorylceramide isolated from Paracoccidioides brasiliensis.

South and Central America. Its structure has been assigned as $\alpha$-D-Man $p-(1 \rightarrow 3)-[\beta-\mathrm{D}-\mathrm{Gal} f-(1 \rightarrow 6)]-\alpha$-DManp-(1 $\rightarrow 2)$-myo-inositol-(1-phosphoryl-1) ceramide (Fig. 5). ${ }^{91}$ Such compound, based on the glycosylation of myo-inositol-(1-phosphoryl-1) ceramide, forms a special class of glycosphingolipids found in plants, yeasts, filamentous fungi and protozoas but so far not in animal cells as mentioned before. Moreover the immunodominant character of the Gal $f$ residue carried by this ceramide antigen could be of valuable interest as serological and taxonomic marker as well as target for immunodiagnostic agents. The presence of the $\alpha$-D-Gal $f$ unit has also been demonstrated recently in the $\alpha-\mathrm{D}$ Galf-(1 $\rightarrow 6)-\alpha-\mathrm{D}-\mathrm{Man} p$ side chains of $P$. brasiliensis cell wall. ${ }^{92}$ This polysaccharide appeared to be shared by the members of the Onygenales but is not present in galactomannans of other fungal genera.

\subsection{Bacteria}

Glycoconjugate structures including the D-Gal $f$ unit in the 1,2-trans anomeric configuration have been found in many other microorganisms, not necessarily pathogenic, including Gram-negative and more rarely Gram-positive bacteria. ${ }^{32}$ Once again, the D-Galf-containing conjugates appeared to be essential for virulence in many pathogenic organisms. These include the lipopolysaccharide (LPS) O-antigens of an increasing number of Gram-negative bacteria, ${ }^{93-95}$ such as that of
Escherichia coli K-12 $2^{53,96}$ (Fig. 6A) or from the enteroinvasive $E$. coli $\mathrm{O} 164^{60}$ as well as the Klebsiella pneumoniae $\mathrm{O}$-antigen repeating unit galactan- $\mathrm{I}^{97}$ (Fig. 6B). They also could be found in extracellular or capsular polysaccharides of a variety of both Gram-negative and Grampositive bacteria. ${ }^{98-101}$

A very recent work reported the structural identification of a unique poly(glycerophosphate) lipoteichoic acid from a Gram-positive bacterium, Streptococcus sp. closely-related to Streptococcus pneumoniae. ${ }^{102}$ This lipoteichoic acid is the first example in which a monohexosylglycerol, 3-O-( $\beta$-D-Galf)-1,2-di- $O$-acyl-sn-glycerol, serves as the glycolipid anchor. Moreover, with an average of 10 glycerophosphate residues, it is the shortest known to date (Fig. 7). It is also interesting to note that

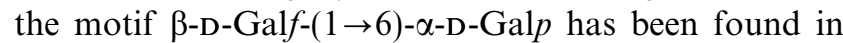
the EPS of human beneficial bacterial strains such as Lactobacillus rhamnosus isolated from human intestinal flora ${ }^{103}$ or from Steptococcus thermophilus produced in skimmed milk. ${ }^{104}$ Nevertheless, little is known about the role of EPS in the adherence of lactobacilli to epithelial cell surfaces. ${ }^{105}$

Finally, the structure of a sulfated polysaccharidepeptidoglycan complex produced by Arthrobacter sp. was characterized by NMR spectroscopy. This revealed that the sulfated polysaccharide contains a repeating unit composed of a trisaccharidic motif [6)- $\beta$-D-Galf$(1 \rightarrow 6)-\beta$-D-Galf- $(1]_{n}$ with $\beta$-D-Glc $p$ linked to one of the Gal $f$ through a $(1 \rightarrow 2)$ linkage. ${ }^{106}$ The sulfated positions were identified at $\mathrm{C}-3$ and $\mathrm{C}-5$ of the $\beta$-glucosylated Gal $f$ unit, and at C-2 or C-3 of the other Galf residue (Fig. 8). This sulfated polysaccharide-peptidoglycan complex

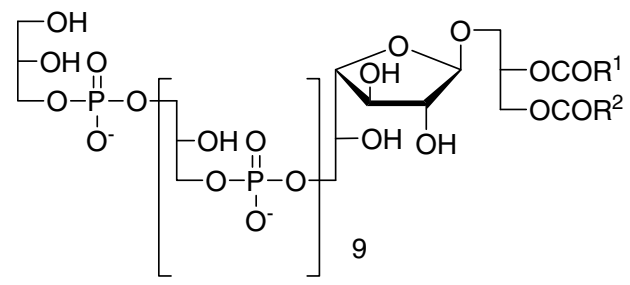

Figure 7. Proposed structure of the poly(glycerophosphate) lipoteichoic acid from Streptococcus sp. DSM 8747.

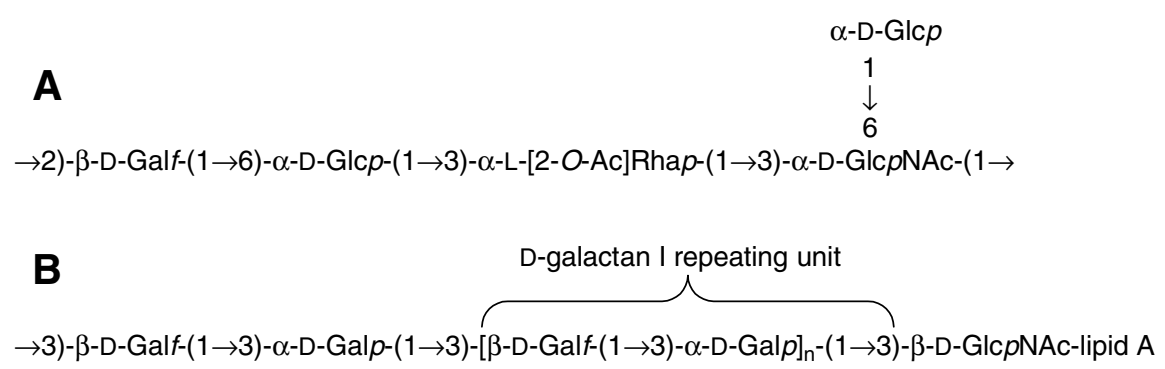

Figure 6. Galf-containing glycoconjugate structures of Gram-negative bacteria. (A) Escherichia coli K-12 LPS O-antigen repeating unit. (B) Klebsiella pneumoniae O-antigen repeating unit galactan-I. 


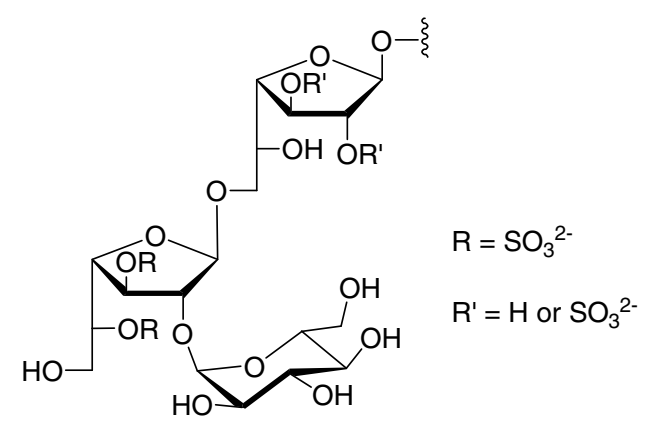

Figure 8. Sulfated trisaccharidic repeating unit of the polysaccharidepeptidoglycan complex produced by Arthrobacter sp.

was previously shown to present antitumour activity due to inhibition of angiogenesis. ${ }^{107}$ Moreover, whereas galactofuranan polysaccharides from bacterial cell wall had been reported previously, this one appeared to be unique due to the presence of sulfate groups.

As far as D-Fruf is concerned, it has been demonstrated that many bacteria build polyfructosides named levan consisting in $\beta$ - $(2 \rightarrow 6)$-linked $\mathrm{D}$-Fru $f$ with a terminal non-reducing D-Glc $p$ unit. ${ }^{108}$ Little is known about their function in bacteria. Very recently, cyanobacterial oligosaccharides $\alpha$-D-Glc $p(1 \rightarrow 2)_{n}-\beta$-D-Fru $f(n \leqslant 9)$ were isolated from Nostoc species. ${ }^{109,110}$ Their role as natural thermoprotectants has been suggested.

\subsection{1,2-cis Hexofuranosides in bacteria}

It should be underlined that the $\mathrm{D}-\mathrm{Gal} f$ unit in the rare 1,2-cis configuration is sometimes present in the previously mentioned oligosaccharides. This is the case in some bacterial strains of Clostridium thermocellum, ${ }^{111}$ which produce a high molecular-mass, cellulose binding, multicellulase-containing protein complex, termed the cellulosome. Structural analysis of the latter revealed a few tetrasaccharidic units incorporating an $\alpha$-D-Gal $f$ core (Fig. 9). Other $\alpha$-D-Gal $f$ containing polysaccharidic structures have been identified in various bacteria ${ }^{112,113}$

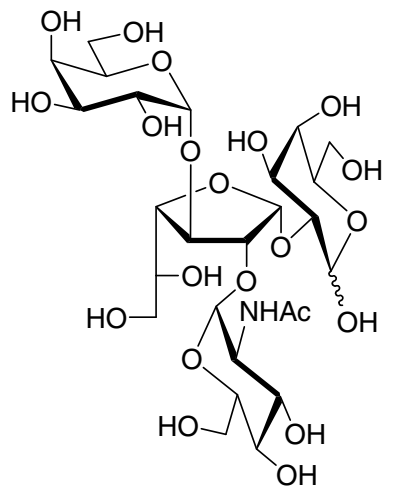

Figure 9. $\alpha$-D-Galf containing fragment of the cellulosome from Clostridium thermocellum. as well as in other microorganisms such as the fungus Adopus dedicuus. ${ }^{114}$

Surprisingly, this 1,2-cis configuration appeared to be less uncommon considering the occurrence of Fuc $f$ containing glycoconjugates. Whereas Fucf naturally exists in both $\mathrm{D}$ - and $\mathrm{L}$-series, derivatives of the latter are rare even if this enantiomer is the most abundant one. For example, a $C$-L-fucofuranosyl compound is produced by Streptomyces collinus ssp. albescens and by Streptomyces gilvotanareus. ${ }^{115-119}$ This novel C-glycosyl compound, named toromycin or gilvocarcin $\mathrm{V}$, depending on the producing organism, has revealed antibiotic and antitumoural activities. ${ }^{117,118}$ Another antibiotic produced by Streptomyces hygroscopicus NRRL 2388, and named hygromycin $\mathrm{A}$, was recently shown to contain a 5-deoxy- $\alpha$-L-Fuc $f$ moiety. ${ }^{120}$ Moreover, glycoconjugates including the D-Fuc $f$ unit have been identified in bacteria and appeared to exist only in the 1,2-cis anomeric configuration (Table 2). For instance, the Gram-positive bacterium Eubacterium saburreum produces antigenic homoor heteropolysaccharides containing a linear chain composed of D-glycero-D-galacto-heptose (Hep) as their core structure, as well as $\alpha$-D-Fuc $f$ residues in some chemotypes such as E. saburreum T15 and T19. ${ }^{121,122}$ These bacterial strains are frequently isolated from human dental plaques, periodontal pockets and infectious dental pulp. $\alpha$-D-Fuc $f$ components are also found in specific structures of the outer membrane polysaccharides of phytopathogenic species, such as Xanthomonas or Pseudomonas syringae and are thought to play a decisive role in host-parasite interactions. ${ }^{123,124}$

Finally, the D-Glc $f$ residue has been identified as a phosphate-linked nucleotide derivative, agrocine 84, produced by the Agrobacterium tumefaciens K84 strain. It has been shown that it acts as a natural antibiotic, controlling crown gall on stone fruit trees, caused by the sensitive phytopathogenic strain Agrobacterium radiobacter (Fig. 10). ${ }^{126-130}$ Absolute configuration at the anomeric position has not been determined yet.

\subsection{Plants and other eukaryotic organisms}

2.6.1. Plants. The presence of different hexofuranosides has been demonstrated in natural structures of plants. For instance, a new purine derivative including a D-Glc $f$ unit and presenting cytokinin activity was isolated from the fruits of Zantedeschia aethiopica (Fig. 11A). ${ }^{131}$ As far as the D-Glef unit is considered, this is the first natural $C$-glucofuranosyl chromone reported. It was isolated from the leaves of Aloe barbadensis $^{132}$ and named neoaloesin A (Fig. 11B). Moreover, the prymnesin-1 toxin (Fig. 11C), isolated from the red tide alga Prymnesium parvum, was shown to contain three $\beta$ D-Galf residues as glycosidic units of the $\mathrm{C}_{90}$ unbranched carbon chain. This unique molecule possesses rare structural features including four 1,6-dioxadecalin 
Table 2. Natural $\alpha$-D-Fuc $f$ containing glycoconjugates

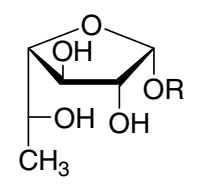

$\boldsymbol{\alpha}$-D-Fuc $f-(1 \rightarrow \mathrm{X})$

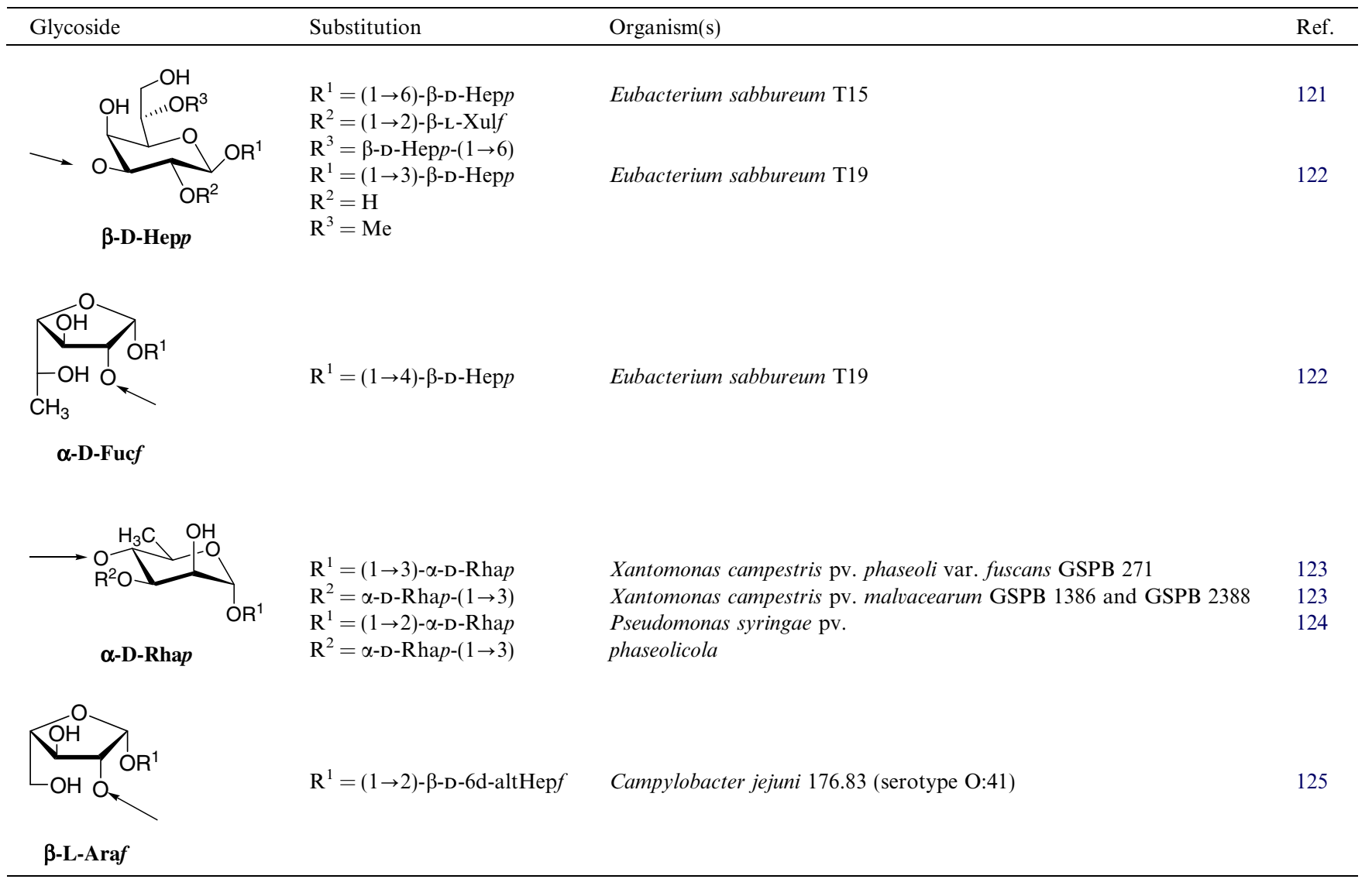

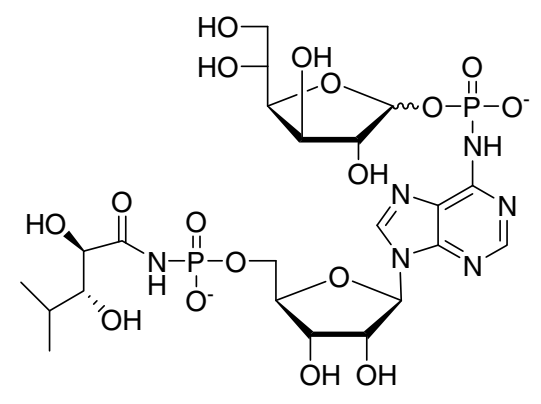

Figure 10. D-Glc $f$ phosphate-linked nucleotide derivative produced by the K84 Agrobacterium tumefaciens, agrocine 84.

units, conjugated double and triple bonds as well as chlorine atoms and reveals potent ichthyotoxic and haemolytic properties. ${ }^{133}$

Besides the common $\alpha$ - and $\beta$-glucans, the branched galactomannans previously isolated from lichens contain $\beta$-D-Gal $p, \alpha$-D-Man $p$ or D-Glc $p$ but rarely $\beta$-D-Galf.
Unusual galactomannan structures have been recently isolated from the lichen Roccella decipiens. ${ }^{51}$ Here, two galactomannan fractions appeared to be substituted by a $\beta$-D-Gal $f$ unit at the non-reducing end, at O-5 and/ or O-6 position. In the same way, the presence of a fungus-type $\beta$-galactofuranan was unexpectedly demonstrated in the cultivated Trebouxia photobiont (cyanobacterial strain) of Ramalina gracilis ${ }^{51}$ and in the Scytonema sp. photobiont of the lichen Dictyomema galbratum. ${ }^{134}$ Moreover, a D-Man $f$ residue has been identified in a unique glycoconjugate isolated from another lichen species Evernia prunastri. ${ }^{135}$

With regard to Fruf, only the D-enantiomer has been reported in nature and it is generally found in the $\beta$-configuration, although glycans with $\alpha$-Fru $f$ residues are known from Zymomonas mobilis and Yersinia intermedia. ${ }^{136,137}$ The most abundant fructofuranoside is obviously sucrose $[\beta-\mathrm{D}-\mathrm{Fru} f-(2 \rightarrow 1)-\alpha-\mathrm{D}-\mathrm{Glc} p$, Fig. 12 A1] isolated from sugar beet and sugar cane. However, bacteria produce polysaccharides that contain $\beta$-fructo- 
A

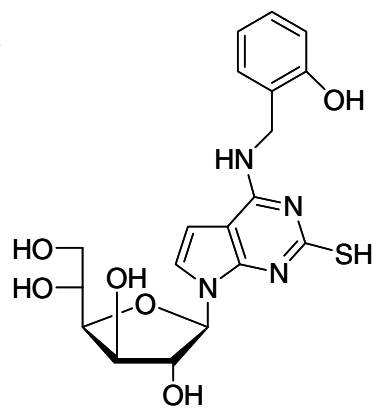

B<smiles></smiles>

\section{C}

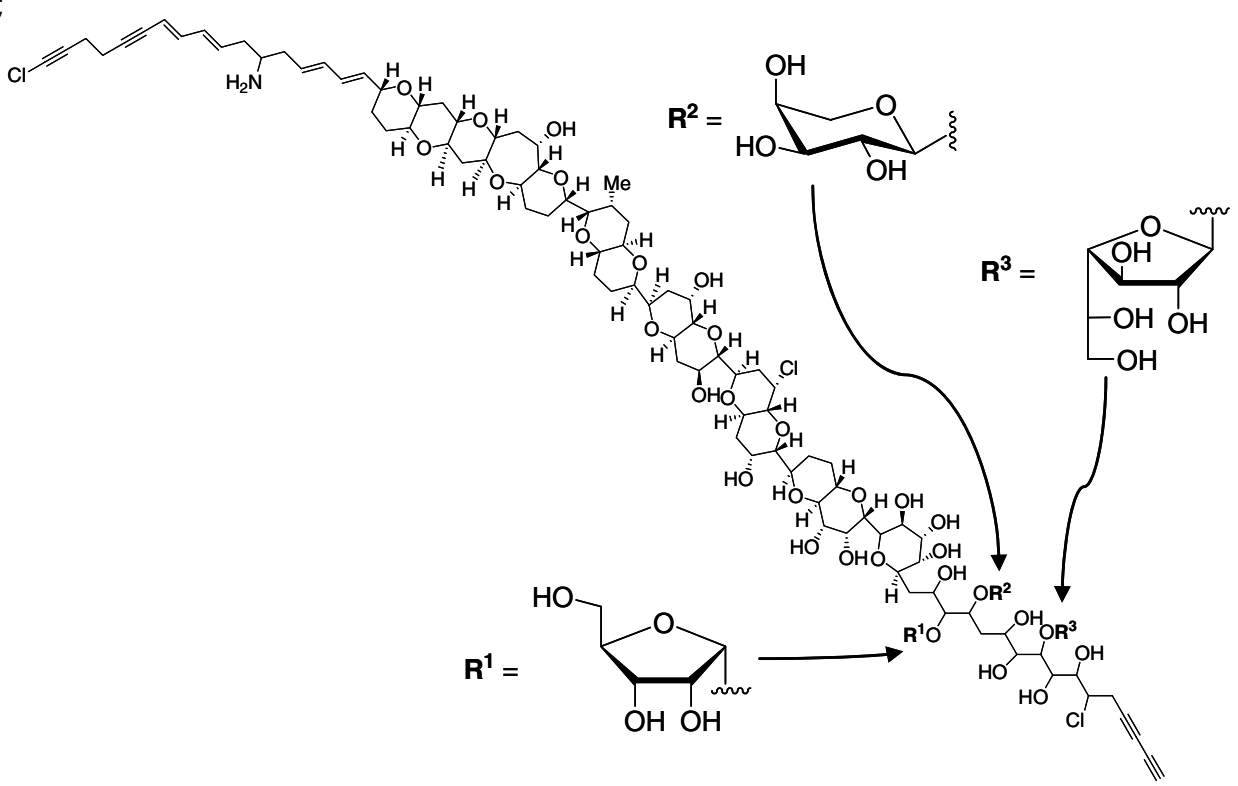

Figure 11. (A) The D-Glcf-containing purine derivative isolated from the fruits of Zantedeschia aethiopica. (B) The $C$-Glc $f$ derivative from Aloe barbadensis, Neoaloesin A. (C) Structure of prymnesin-1-toxin.
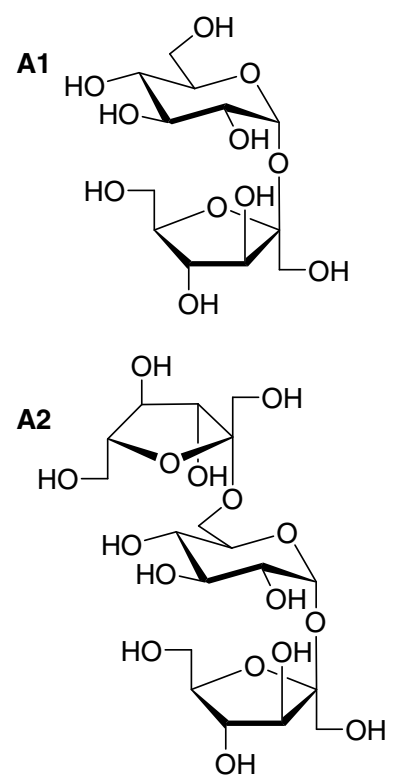

B1

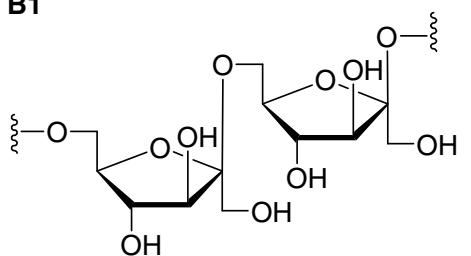

B2
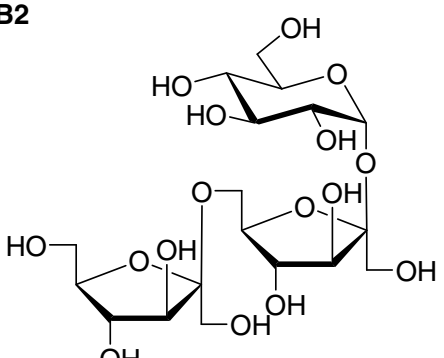

C1

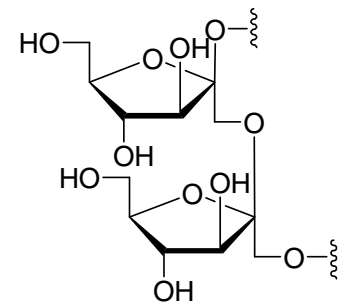

C2

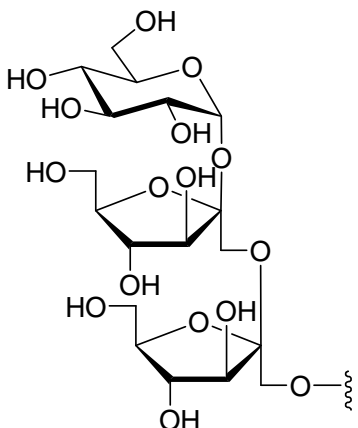

Figure 12. The three trisaccharidic biosynthetic precursors of fructosans produced by plants: (A1) sucrose (B1) $\beta$ - $(2 \rightarrow 6)$-linked Fruf residue found in levan-type polysaccharides, and (C1) $\beta$ - $(2 \rightarrow 1)$-linked Fruf residue found in inulin-type polysaccharides Examples: (A2) neokestose (B2) 6-kestose and (C2) 1-kestose. 
furanoside residues (see Section 2.4). In addition, plants produce polyfructofuranosides including inulin-type and levan-type structures, which are composed of $\beta$ $(2 \rightarrow 1)$ - or $\beta-(2 \rightarrow 6)$-linked Fruf residues, respectively $(\mathbf{B 1}, \mathbf{B 2}, \mathbf{C 1}, \mathbf{C 2}) .{ }^{20}$ Highly branched structures comprising both $(2 \rightarrow 1)$ - and $(2 \rightarrow 6)$-linked $\beta$-fructofuranosyl units have also been encountered in Gramineae. ${ }^{138} \mathrm{Be}-$ sides starch, fructans are the most widespread reserve polysaccharides in higher plants. Moreover, they can reach the size of $10^{6}$ Dalton and have been implicated in drought and frost tolerance. ${ }^{139}$ Three types of fructosans have been characterized and their structures are derived from three trisaccharidic biosynthetic precursors. Neokestose (A2) has been isolated from the storage tissues of onion (Allium cepa) and from the roots of Asparagus officinalis. 6-Kestose $[\beta-\mathrm{D}-\mathrm{Fru} f-(2 \rightarrow 6)-\beta$-D-Fruf$(2 \rightarrow 1)-\alpha-D-G l c p$, B2] from the levan-type group has been found for instance in the leaves of some Gramineae such as barley (Hordeum vulgare) or in wheat (Triticum aestivum). 1-Kestose [ $\beta$-D-Fruf- $(2 \rightarrow 1)-\beta$-D-Fruf- $(2 \rightarrow 1)$ $\alpha$-D-Glc $p$, C2] is the biosynthetic precursor of inulin in many plants from the Asteraceae family such as chicory (Cichorium intybus L.) or Jerusalem artichoke (Helianthus tuberosus L.). Kestoses are of interest because of three main attributes: (i) their sweetness, (ii) the fact that they are hardly hydrolyzed by digestive enzymes and (iii) they are preferentially consumed by beneficial bacteria in the human colon. They are thus used in food as non-caloric and non-cariogenic sweeteners as well as bifidus-growth factor and prebiotic nutriments. ${ }^{140-142}$ They are industrially prepared by the partial hydrolysis of inulin extracted from chicory or by enzymatic synthesis from sucrose. ${ }^{143}$ In addition, alkyl D-fructosides as well as oligosaccharides incorporating the $\beta$-D-Fru $f$ unit, generally uncommon in plants, have been isolated very recently from diverse plant species: Saussurea lappa, ${ }^{144}$ Vigna mungo L., ${ }^{145}$ A. officinalis, ${ }^{146}$ the fruits of Morinda citrifolia. $^{147}$

2.6.2. Marine sponges. The $\alpha-\mathrm{D}-\mathrm{Gal} f$ unit linked to a $\beta$ D-Gal $f$ unit has been identified in a glycosphingolipid produced by the marine sponge Agelas sp. ${ }^{54}$ This molecule, termed agelagalastatin (Fig. 13) displays antitumoural activity against certain human cancer cell lines.

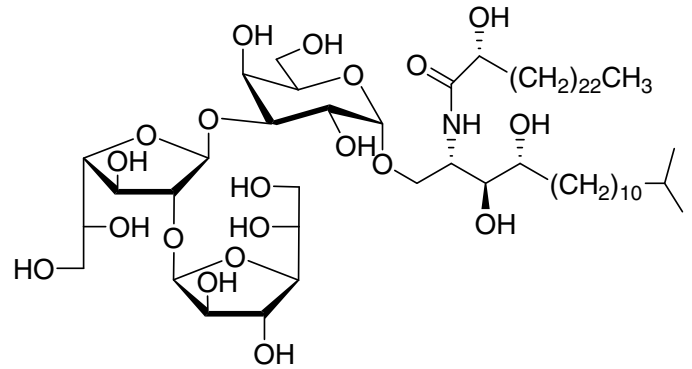

Figure 13. The glycosphingolipid produced by Agelas sp., agelagalastatin.

This furanosyl-ceramide constitutes one of the very rare natural galactofuranosyl-ceramides, which are known as characteristic membrane components of eukaryotic cells. Indeed, these natural glycosphingolipids so far isolated from marine sponges share the same core structure: a ceramide directly glycosylated with a D-Galf unit or with a D-Galf-(1 $\rightarrow 3)-\mathrm{D}-\mathrm{Gal} p$ disaccharidic unit. $^{55,148}$

2.6.3. Starfish. Three gangliosides were obtained from the whole body of starfish Acanthaster planci and named acanthagangliosides AG-1, AG-2 and AG-3. ${ }^{149,150}$ The structure of the oligosaccharide moiety was determined by NMR spectroscopy and appeared to differ from the terminal monosaccharide moiety. The non-reducing $\beta$ D-Galf in AG-2 and AG-3 is linked to C-3 of an $\alpha$-DGal $p$ entity whereas the terminal $\beta$-L-Fuc $f$ (Fig. 14) in AG-1 is linked to C-4 of an $\alpha$-D-Gal $p$ unit. The gangliosides of $A$. planci have a terminal characteristic furanosetype sugar unit, an oligosaccharidic structure only found in starfish belonging to the order of Spinulosa.

2.6.4. Archaebacteria. In archaebacteria, the tetraether bipolar lipids are thought to form monolayers, allowing the microorganisms to maintain membrane integrity in harsh environments (hot springs, sub-marine volcanic fields, Antarctic ice-fields, etc.). ${ }^{21}$ The presence of $\beta$-DGalf units in these lipids is noteworthy. Even if these moieties are supposed to stabilize the membrane structure by interglycosyl headgroup hydrogen-bonding, the occurrence of the furanosyl sugar in extreme environ-

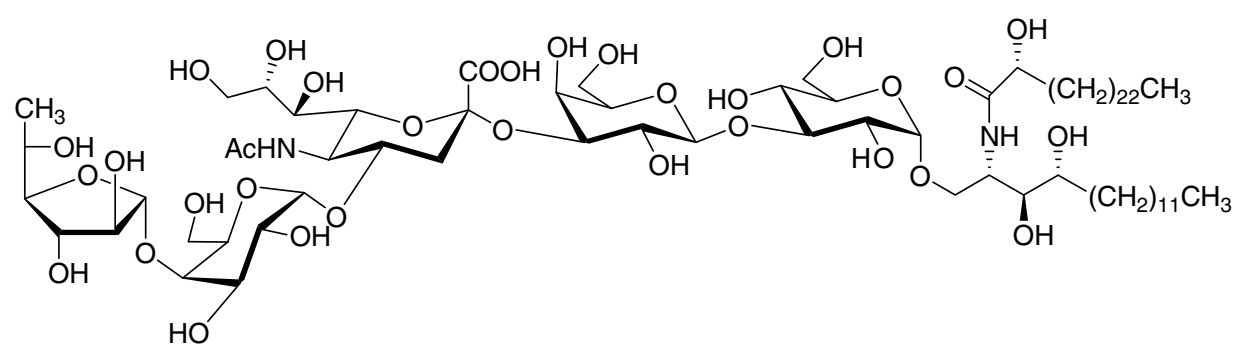

Figure 14. L-Fucf-containing acanthaganglioside AGl of the starfish Acanthaster planci. 
ments, where the archaea proliferate, remains a surprising point. Indeed, the furanosides are known to be much more rapidly hydrolyzed than their pyranosyl counterparts. $^{151}$

\section{Recent advances in the synthesis of hexofuranosyl- containing oligosaccharides and conjugates}

Most of the time, required furanosyl intermediates are more easily available in significant yields starting from pentoses than from hexoses. Indeed, both acid-catalyzed Fischer glycosidation of reducing hexoses and their direct acylation under standard conditions afford hexofuranosyl derivatives and hexopyranosyl compounds, respectively. Consequently, the synthesis of hexofuranose-containing glycosides and conjugates involves methodologies specifically dedicated to hexoses. Some important results were obtained for D-Gal, for which perbenzoylation had to be carefully controlled at high temperature to give the desired furanose, ${ }^{152}$ and for DGlc whose peracetylation was performed in the presence of boric acid. ${ }^{153}$ An alternative and more general approach proposed first to lock the hexofuranosyl ring by Fischer glycosylation of long chain alcohols. This reaction was promoted by ferric chloride in the presence of additional salts, such as calcium or barium chloride. ${ }^{154-156}$ The alkyl chain acts here as a temporary protection of the anomeric centre, thus preventing any ring expansion. Protecting group manipulation and activation reactions further yielded a large panel of furanosyl synthons, even the key peracylfuranoses. ${ }^{157}$ A direct synthesis of alkyl hexosides was also developed starting from free hexoses but using an electrophilic reagent, a strong base, and $N, N^{\prime}$-dimethylpropyleneurea (DMPU) as a solvent. ${ }^{158} \mathrm{Up}$ to now, only alkyl $\alpha$-D-galactofuranosides were efficiently obtained under such conditions. With regard to the last example, the aliphatic chain was also interestingly replaced by a pentenyl one so that the preparation of $n$-pentenyl hexofuranosides was performed in only one step. ${ }^{159}$

On the basis of these general considerations, the chemical synthesis of a fragment of natural hexofuranose-containing saccharides was described. ${ }^{2,12}$ Assuming that $\mathrm{D}$-Gal is the most widespread hexose in such compounds, much effort was dedicated to its chemistry. Approximately all of the most known families of donors were used to prepare di- and trisaccharides: furanosyl halides, ${ }^{160}$ in spite of their low stability, 1-acyl donors, ${ }^{161-163}$ even if they are a priori less reactive than other donors, $n$-pentenyl furanosides, ${ }^{159,164}$ trichloroacetimidates, ${ }^{163,165-167}$ thiofuranosides, ${ }^{157,163}$ sulfoxides $^{168,169}$ and also recently thioimidates. ${ }^{163,170-173}$ Related studies efficiently afforded disaccharidic sequences such as $\beta$-D-Galf- $(1 \rightarrow 5)-\beta$-D-Gal $f$ and $\beta$-DGal $f-(1 \rightarrow 6)-\beta$-D-Gal $f,{ }^{163,166,174-176} \quad \beta$-D-Gal $f-(1 \rightarrow 6)-$
$\operatorname{Man} p^{176}$ and $\beta$-D-Galf- $(1 \rightarrow 4)-G l c p$ NAc. ${ }^{167}$ More challenging tasks deal with the synthesis of higher oligosaccharides characterized by the presence of internal galactofuranosyl entities. This required a regioselective glycosylation of a furanosyl acceptor and the activation of the furanosyl anomeric centre, or vice versa. While standard approaches were nicely carried out for the synthesis of hexagalactosides, ${ }^{165}$ de Lederkremer and coworkers interestingly proposed suitably protected derivatives of D-galactono-( $1 \rightarrow 4)$-lactone as key precursors so that they were able to synthesize trisaccharidic units of the galactan produced by $M$. tuberculosis ${ }^{177}$ and Leishmania species ${ }^{178}$ (Scheme 1).

On another hand, Ning and Wang synthesized a galactofuranose disubstituted in positions 5 and 6 by an arabinofuranosyl unit and a galactosyl one, respectively (Scheme 2). ${ }^{179}$ This one-pot preparation relied on the galactosylation of 3-O-benzoyl-1,2- $O$-isopropylidene-Dgalactofuranose at the primary position followed by 5 $\mathrm{O}$-arabinofuranosylation of the resulting disaccharide. Final deprotection allowed the authors to obtain a reducing Gal $f$ since position 5 was no more reactive for cyclization. The key monoacetonide template was also used for the first synthesis of the trisaccharide repeating unit of the cell wall galactans of Bifidobacterium catenulatum and its hexasaccharidic dimer. ${ }^{166}$

Much more complex natural galactofuranose-containing oligosaccharides were also prepared according to multi-step syntheses. The first examples described in 2000 dealt with a subtle approach to hexa- and heptasaccharidyl myo-inositols found in the lipophosphoglycans of Leishmania parasites. ${ }^{162}$ The key steps of this synthesis were the use of (i) a small number of orthogonal protecting groups and glycosyl donors, and (ii) a tetraacetyl galactofuranose derivative having a free hydroxyl function at position 3. The latter compound was first glycosylated and subsequently engaged without any further activation in coupling with an inositol-containing acceptor (Fig. 15). More recently, peracetylated Galf was also proposed as an efficient furanosyl donor for the outstanding synthesis of the pseudo-octasaccharidic part of the lipopeptidophosphoglycan produced by the infectious agent $T$. cruzi. $^{161}$ These molecules are characterized by hexofuranosyl residues with a 1,2-trans anomeric stereochemistry that was obtained via the anchimeric assistance of a 2-O-acyl group.

As for their pyranosyl counterparts, the synthesis of 1,2-cis hexofuranosides presents increased difficulty not only due to the relative cis orientation between the aglycon and the group at position 2 , but also because hindrance effects compete with anomeric ones. Nevertheless, during the last five years, important improvements were made for the stereocontrolled synthesis of 1,2-cis hexofuranosides. O-Glycosylation specifically leading to $\alpha$-D-galactofuranosides was first 


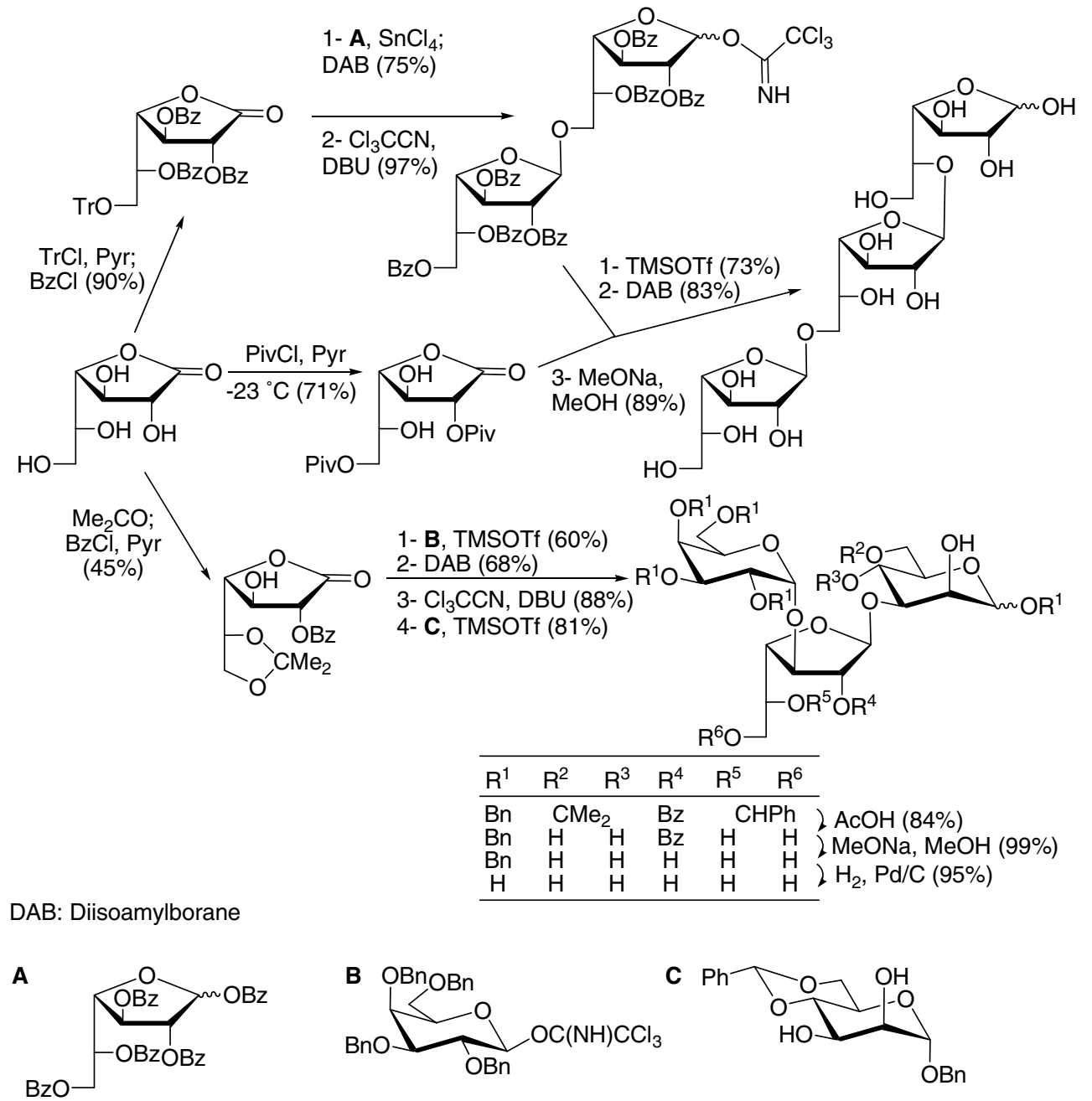

Scheme 1. Strategy relying on the use of galactonolactone for the synthesis of a galactofuranosyl containing trisaccharide.
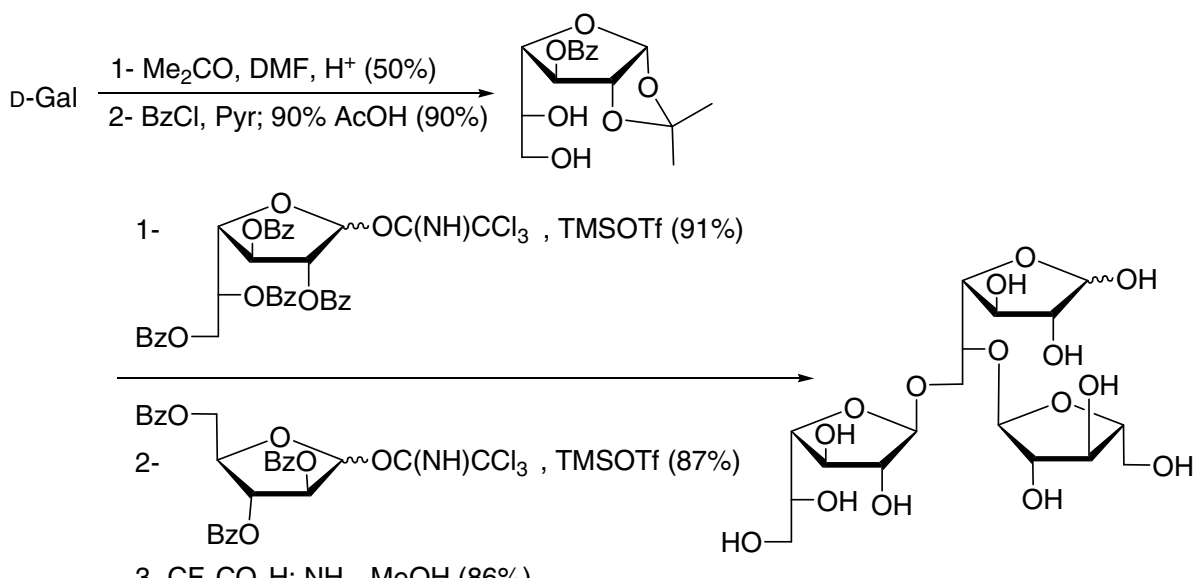

Scheme 2. Example of synthesis of an heteroglycofuranosyl trisaccharide.

proposed by Kinzy and Schmidt who were able to obtain pure alkyl derivatives starting from $\mathrm{D}-\mathrm{Gal}$ and electrophilic reagents and using DMPU as a solvent. ${ }^{158}$ This approach was further applied to the synthesis of the corresponding $n$-pentenyl donor, which offered the opportunity to nicely introduce an acyl protecting group 


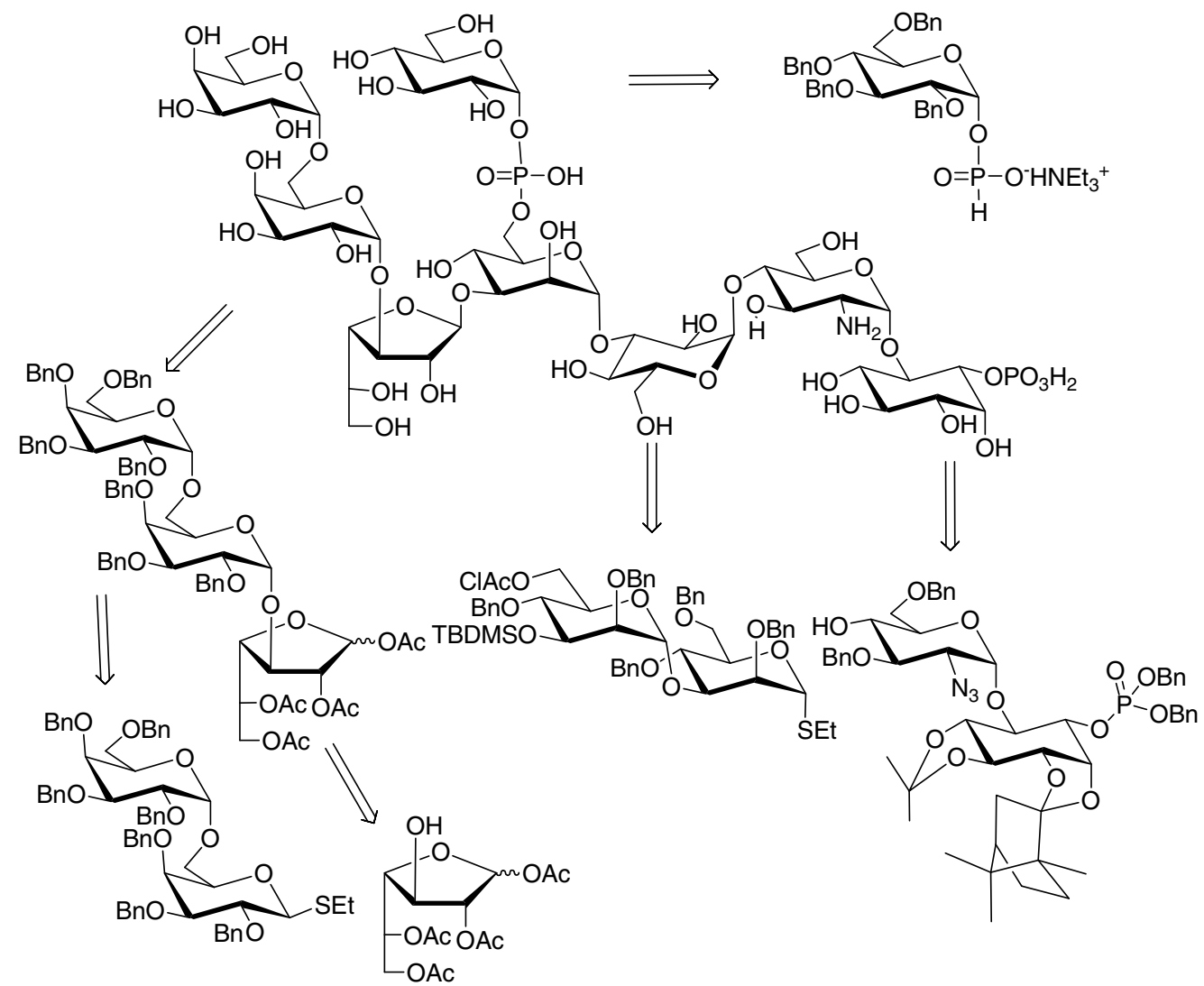

Figure 15. Retrosynthetic scheme for the preparation of the inositolphosphoglycan fragment produced by the Leishmania parasite.

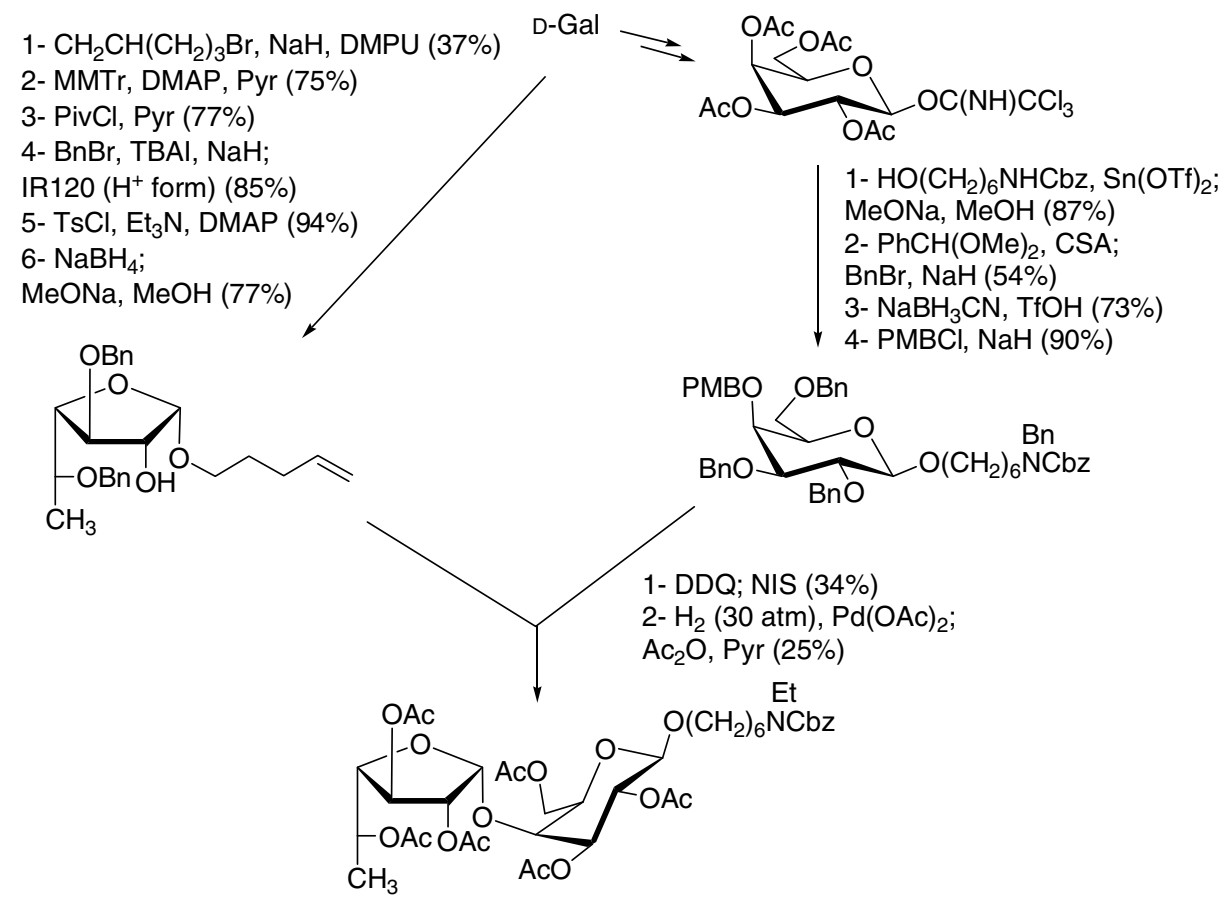

Scheme 3. Synthesis of the $\alpha$-D-Fucf-(1 $\rightarrow 4)-\beta-D-G a l p$ disaccharide.

selectively at position $2 .^{180}$ The resulting galactosyl donor was then converted into a fucofuranosyl donor bearing a 4-methoxybenzyl group at O-2. The latter was required for tethering a galactopyranosyl entity allowing its intramolecular transfer (Scheme 3 ) to yield the first $\alpha$ D-Fucf- $(1 \rightarrow 4)-\beta$-D-Gal $p$ disaccharide. 
Instead of the PMB intermediate, Fairbanks and colleagues favoured the allyl protecting group to mediate intramolecular aglycon delivery to perform the synthesis of three disaccharides containing a non-reducing $\alpha$-Dglucofuranosyl entity (Fig. 16). ${ }^{181}$

Very recently, Lowary's team developed an alternative approach involving the stereocontrolled opening of 2,3-anhydrosugars. This strategy was applied to the preparation of $\beta$-D-arabinosides ${ }^{182}$ but also of $\alpha$-Dgalactosides. ${ }^{169}$ The key epoxide intermediates were efficiently opened with lithium benzylate in the presence of (-)-sparteine (Scheme 4). Having demonstrated that glycosylation reactions were best performed with sulfoxides as donors, and with benzoyl protecting groups at

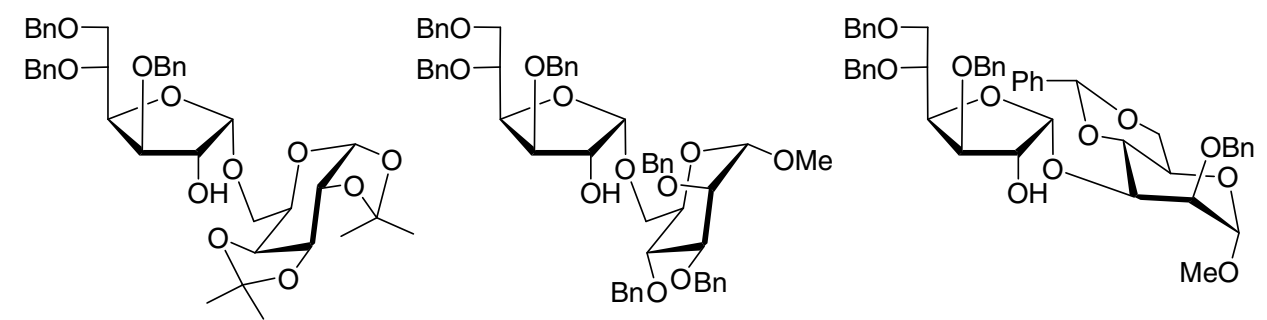

Figure 16. $\alpha$-D-Glucofuranosyl-containing disaccharides.

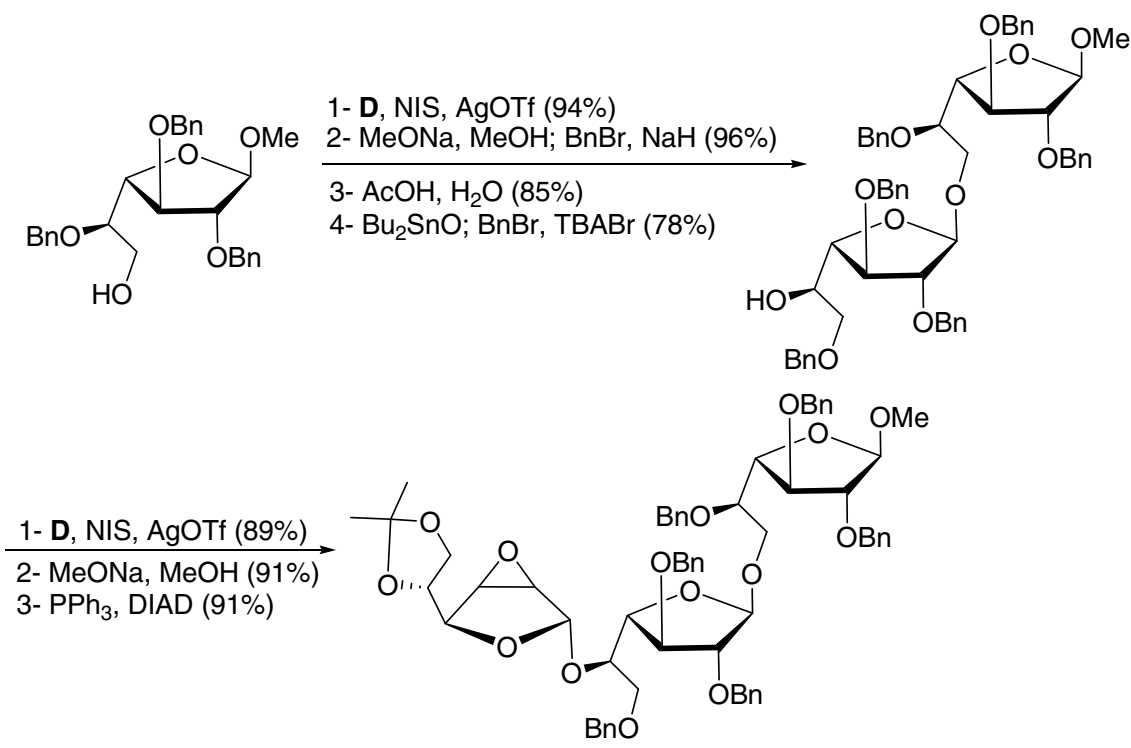

1- $\mathrm{LiOBn}, \mathrm{BnOH}(87 \%)$

2- E, $\mathrm{Tf}_{2} \mathrm{O}(75 \%)$

3- LiOBn, (-)-sparteine (67\%)

4- $\mathrm{Me}_{2} \mathrm{C}(\mathrm{OMe})_{2}, \mathrm{PTSA}(88 \%)$

5- F, BSP/Tf $20(56 \%)$

6- $\mathrm{AcOH}, \mathrm{H}_{2} \mathrm{O}(77 \%)$

7- $\mathrm{H}_{2}, \mathrm{Pd}(\mathrm{OH})_{2}(100 \%)$
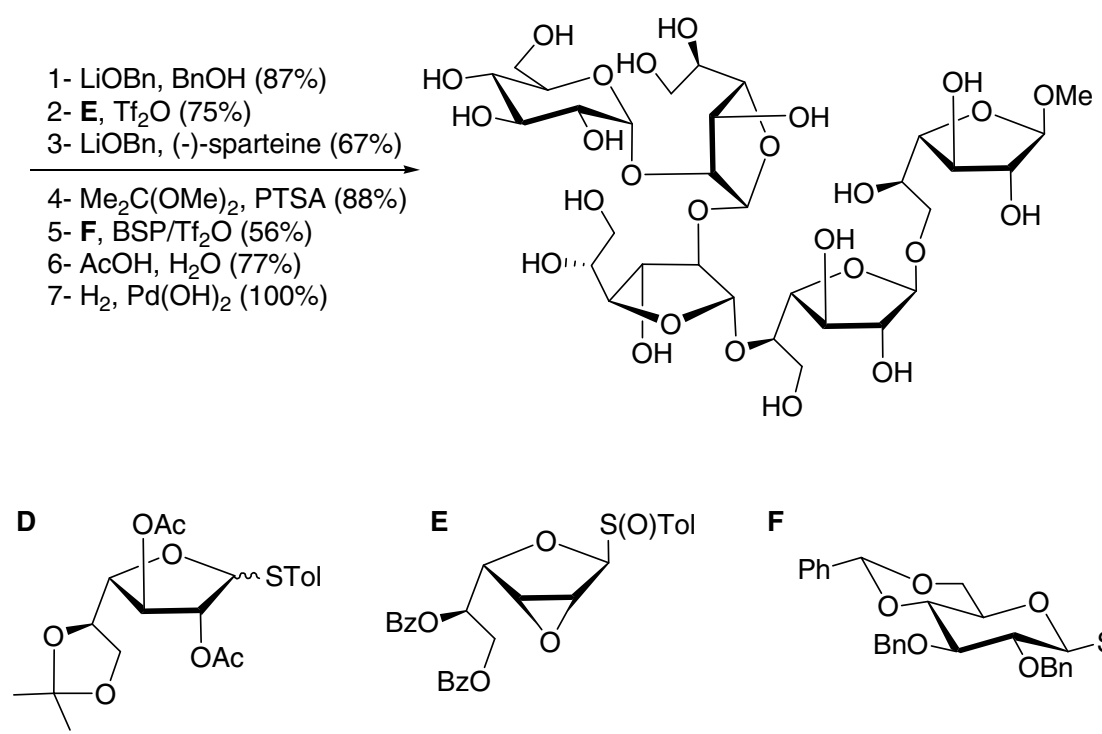

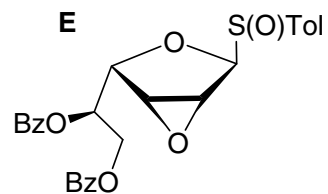

$\mathbf{F}$

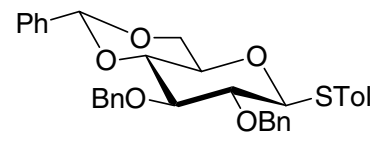

Scheme 4. The 2,3-anhydrosugar approach for the synthesis of varianose. 
positions 5 and 6 for optimum nucleophilic attack, the authors nicely extended their approach to the synthesis of the pentasaccharidic fragment of varianose, a cell wall component produced by Penicillium varians which is structurally characterized by the presence of galactofuranosyl units (i) substituted at O-2, O-5 or O-6, and (ii) having either the $\alpha$ - or $\beta$-configuration. ${ }^{175}$

A most impressive achievement with the preparation of hexofuranosides is related to the total synthesis of marine agelagalastatin (Fig. 13), a glycosyl ceramide whose trisacharidic part is built up with one $\alpha$ - and one $\beta$-galactofuranosyl entity. The 1,2-cis furanosylation was carried out from a $2^{\prime}$-carboxybenzyl galactoside as a donor, which had non-participating protecting groups and which was activated by triflic anhydride in the presence of DTBMP. On the other hand, the first 1,2-trans coupling was orthogonally achieved using a similar donor, but notably protected with a 2-O-acyl group, and using a 2 -(benzyloxycarbonyl)benzyl galactopyranosyl derivative as an acceptor. The resulting trisaccharide was further converted into a glycosyl fluoride to ensure the transfer on a ceramide chain to afford the target agelagalastatin in a yield up to $10 \%$ for 22 steps starting from peracetylated galactofuranose. ${ }^{183}$

Amongst other complex compounds of biological significance, uridine 5'-diphospho (UDP)-furanoses are more particularly important since they are key substrates to investigate the process involved in the hexofuranose incorporation within cell wall glycoconjugates, and therefore to study two families of enzymes, that is, UDP-pyranose mutases and hexofuranosyltransferases. Up to now, UDP- $\alpha-D-G a l f$ is the only natural substrate identified to naturally transfer hexofuranosyl entities. This is the reason why many efforts were dedicated to its synthesis. While enzymatic methods had been proposed earlier, ${ }^{184}$ even for fluorinated analogues, ${ }^{185}$ substantial amounts of UDP- $\alpha-D-G a l f$ were first obtained in 2000 independently by Tsvetkov and Nikolaev, ${ }^{186}$ and Zhang and Liu ${ }^{187}$ via chemical methods. The latter relied on the coupling between $\alpha$-D-galactofuranosyl phosphate $^{188}$ and uridine $5^{\prime}$-morpholidate. Interestingly, this synthesis was further optimized by Kiessling and coworkers who proposed to use a $5^{\prime}-N$-methyl phosphorylimidazolide nucleoside activated at $\mathrm{OH}-2$ and $\mathrm{OH}-3$ by two trifluoroacetyl groups (Scheme 5). ${ }^{189}$ It is finally noteworthy that the labelled UDP- $\alpha-\mathrm{D}-\left[6-{ }^{3} \mathrm{H}\right] \mathrm{Gal} f$ was also synthesized. ${ }^{190}$

An alternative chemical approach was recently developed by our team involving direct coupling between an unprotected thioimidate and a phosphoric acid. This methodology was first validated with dry phosphoric acid and subsequently extended using the acidic form of UDP (Scheme 6). ${ }^{191,192}$

While chemical syntheses of hexofuranosyl conjugates tend to be more and more efficient, the number of methods involving biocatalysts is still quite limited, probably due to the low availability of specific enzymes. Nevertheless, Field and colleagues were able to enzymatically prepare UDP- $\alpha$-D-Galf using a multi-enzyme system containing non-furanosyl specific catalysts. ${ }^{193}$ Concomitantly, progress was also made for the preparation of $O$ hexofuranosides on the basis of chemo-enzymatic approaches. An interesting possibility relies on the use of an $\alpha$-L-arabinofuranosidase. The wild type AbfD3 was indeed efficient enough to recognize and transfer 4-nitrophenyl galactofuranoside ( $p$ NP-Gal $f$ ) to either pyranosyl acceptors in transglycosylation reactions or to $p$ NP-Galf itself in self-condensation dimerizations (Scheme 7). ${ }^{194}$ The versatility of this enzyme was further demonstrated for the preparation of difucofuranosides and fluorinated derivatives. ${ }^{195}$ Recently, the sialylation of galactofuranose-containing oligosaccharides was carried out with a recombinant trans-sialidase to study the impact of the presence of furanosyl entities on the transfer of sialic acid galactopyranosyl residues. ${ }^{196}$ A good way to improve yields consists in mutating wild type enzymes to minimize their hydrolytic ability. ${ }^{197}$ Unfortunately, unprotected furanosyl donors such as fluorides are not suitable substrates because of their instability. Consequently, a field of investigation is now opened to

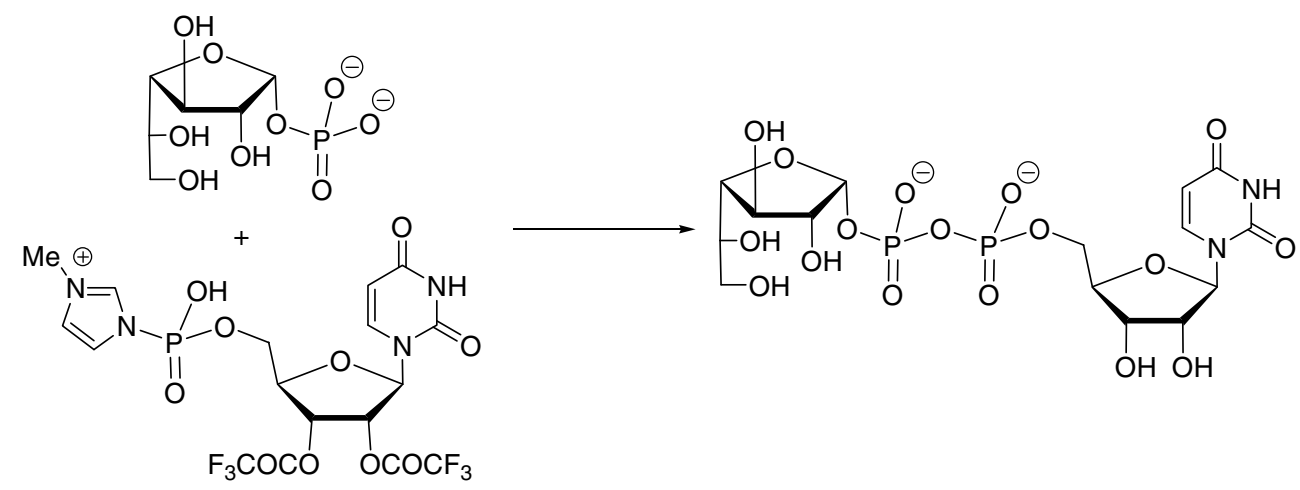

Scheme 5. Synthesis of UDP- $\alpha$-D-Gal $f$ according to Kiessling and co-workers. ${ }^{189}$ 

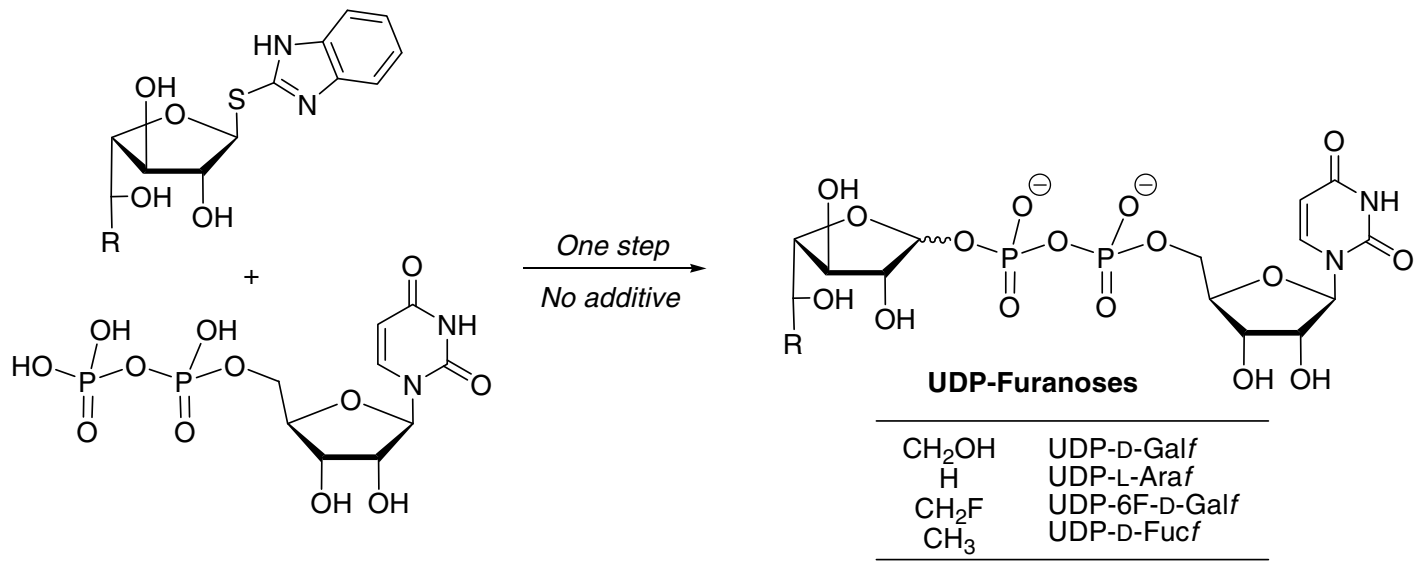

Scheme 6. Synthesis of a panel of furanosyl 1-phosphates and UDP-furanoses starting from thioimidates.

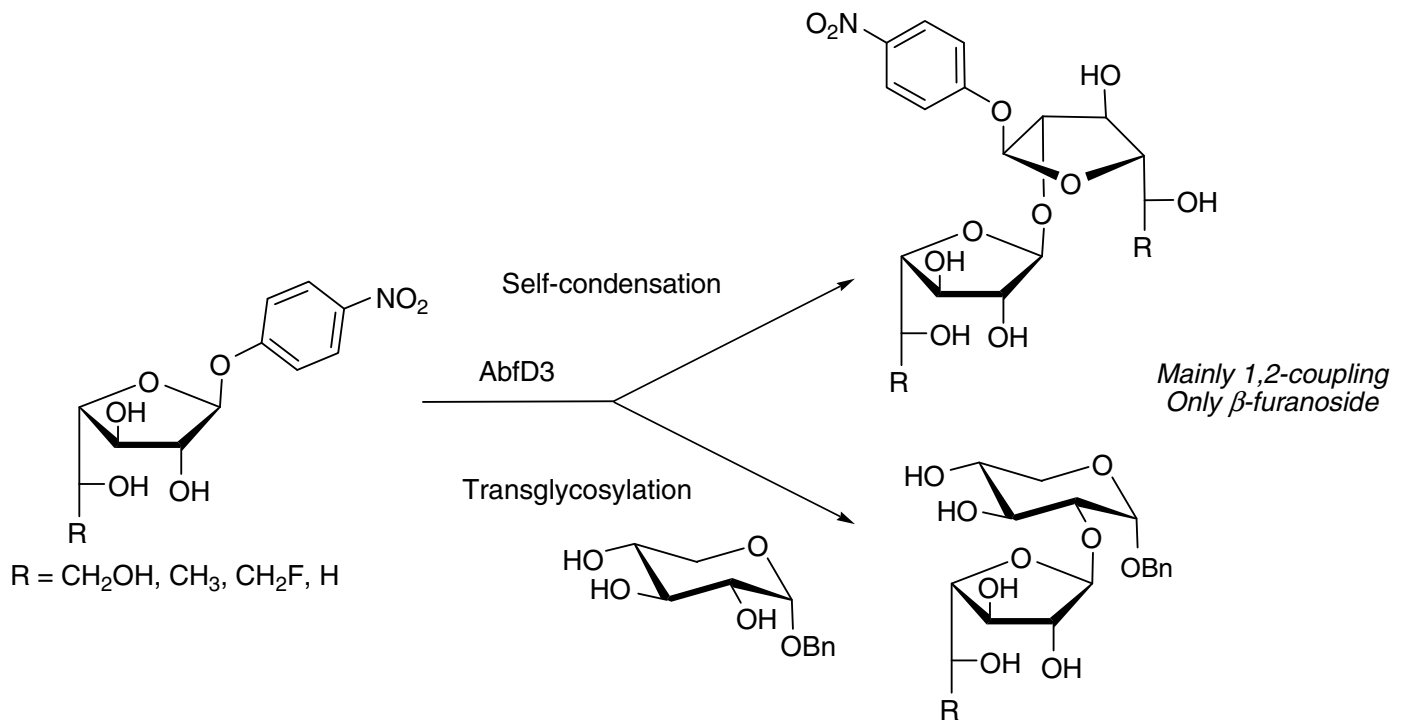

Scheme 7. Chemo-enzymatic syntheses using AbfD3.

extend the previous concept to the synthesis of furanosides.

Finally, the use of more specific furanosyltransferases was also investigated. In 2001, it had been shown that a single enzyme is able to transfer galactofuranosyl residues from UDP- $\alpha-D-G a l f$ to two disaccharidic glycolipid acceptors differing in the branching between both galactosyl moieties. ${ }^{198}$ This study was recently completed by Lowary and co-workers who showed that trisaccharides are better substrates than disaccharides, even for the synthesis of oligogalactans presenting alternating $\beta-(1 \rightarrow 6)$ - and $\beta-(1 \rightarrow 5)$ linkages (Scheme 8$).{ }^{4}$

\section{Hexofuranosides and novel applications}

As discussed previously, hexofuranosides are widely distributed in nature, but essentially in pathogenic organ- isms. Moreover their absence in mammal glycoconjugates suggests that the enzymes involved in the metabolism of such sugars in bacteria, fungi and protozoa would constitute a good target for the design of new drugs. Therefore they have raised the interest of glycoscientists due to their potential biological applications. Besides that particularity, this family of carbohydrates can also be used (like their pyranose counterpart) as regular polyols, with a high potency of hydrogen-bonding and an important stereodiversity. Applications can then be found in the domain of physicochemistry or in chemistry.

\subsection{Biological application}

The most important applications of hexofuranosides rely on the biological field. They proved to be tremendous tools for the study of the UDP-Galp mutase and 


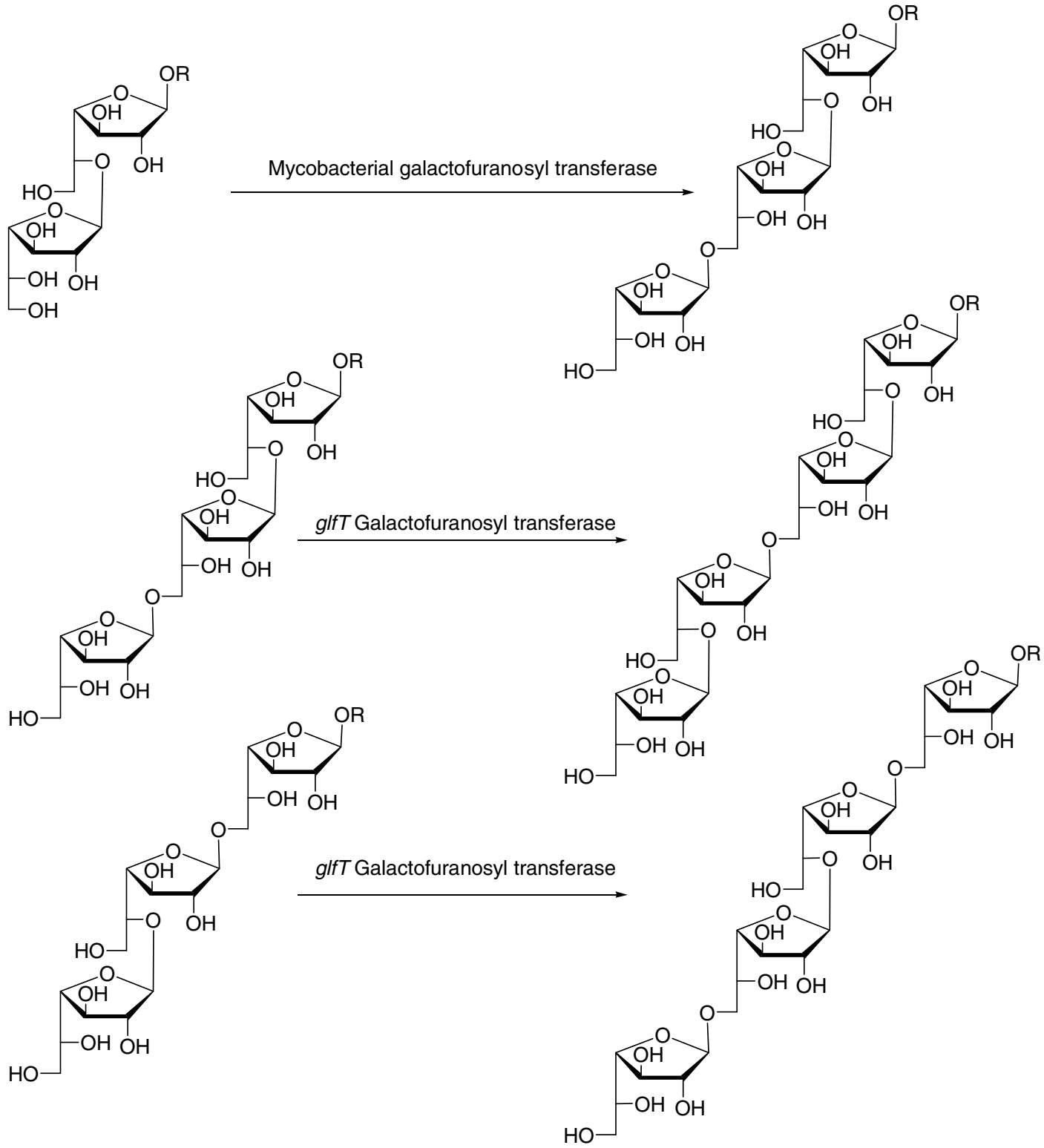

Scheme 8. Chemo-enzymatic syntheses using of oligogalactans using furanosyl transferases.

they can also act as antimycobacterial or antitumour agents. An interesting application has even been described for the induction of erythroid differentiation of human K562 cells using some esters of glucofuranosides and mannofuranosides. ${ }^{199,200}$

4.1.1. Inhibitors of mutase. Up to now, the most studied enzyme involved in the biosynthesis of hexofuranosides is certainly UDP-Gal $p$ mutase which catalyses the isomerization of UDP-Gal $p$ to UDP-Gal $f$. However the detailed mechanism of this flavoenzyme is not yet fully elucidated, although the three-dimensional structure of the protein has been determined by X-ray. ${ }^{186,201}$ The design of analogues is still of tremendous interest, and will lead to a better understanding of this unique process while helping in the development of new therapeutic strategies against tuberculosis, leprosy and other diseases notably caused by mycobacterial infections. These compounds can be divided into two families: one where the furanose entity is conserved and the second one where the oxygen of the five-membered ring has been replaced by another element $(\mathrm{N}, \mathrm{S}, \mathrm{Se})$.

The major drawback of UDP-Gal $f$ is its very low stability in solution, which has raised the difficulty of its synthesis, and has slowed down the progress in the study of the mutase. ${ }^{186}$ To avoid this problem, Sinaÿ and colleagues have achieved the preparation of the $C$-analogue of UDP-Gal $f$ (Fig. 17), obtained in $80 \%$ yield from the corresponding phosphonate and an activated UMP. ${ }^{202}$ This molecule represents the first example of a synthetic inhibitor of UDP-Galp mutase. It is thus of potential interest as antimycobacterial agent, as active molecule 


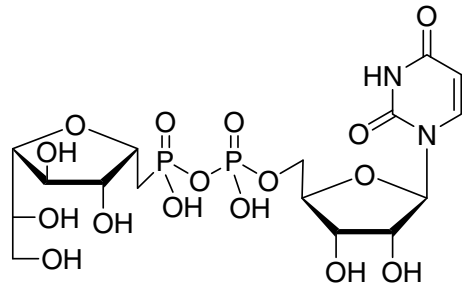

Figure 17. $C$-Analogue of UDP-Galf.

against $T$. cruzi (Chagas' disease) and as a stable analogue for UDP-galactopyranose mutase crystallization studies.

A couple of years later, Zhang and Liu have prepared the C-2 and C-3 fluorinated derivatives (Fig. 18) and used them as probes in order to gain insights into the catalytic mechanism. ${ }^{203}$ Especially the $3-\mathrm{F}$ analogue represents an effective inhibitor and the inactivation of the enzyme can be irreversible under non-reducing conditions. This study strongly suggests the involvement of a covalent intermediate formed between the sugar and a catalytic nucleophile such as the flavine cofactor itself.

Recently, a collaboration between Vincent and Sinaÿ groups has lead to the emergence of a new series of time-dependent inactivators. ${ }^{204,205}$ These nucleosidediphospho-exo-glycals (Fig. 19), fluorinated or not at the unsaturated exo-position, allowed to clarify the catalytic properties of the mutase and to postulate that the inactivation mechanism must involve go through a sequence of two-electron processes, that is, protonation of the anomeric position and then nucleophilic addition, as opposed to a single electron transfer and then a radical coupling of the nucleophile.

However, partly due to these studies, the presence of an oxacarbenium ion like intermediate in the transition state of the isomerization process is widely admitted. ${ }^{206}$ Thus, oxonium mimics, like in the strategies thought for glycosidases and glycosyltransferases inhibition, have also been considered for the inhibition of the mutase. So, polyhydroxylated piperidine and pyrrolidine, also often called azasugars, provide a powerful set of inhibitors of glycosyltransferases as well as glycosidases. Hence, Lee et al. have synthesized the two pyrrolidine analogues of Gal $f$ shown in Figure $20 .{ }^{207}$ Even if the yields were moderate, both compounds inhibited the mutase as well as the in vitro biosynthesis of the mycobacterial galactan at a concentration of $200 \mu \mathrm{g} / \mathrm{mL}$. Interestingly, their activity was specific to that particular enzyme, since negligible effects were observed on galactosidase. The synthesis of 1,4-dideoxy-1,4-imino-Dgalactitol was further improved to an overall yield of $42 \%$ using a five-step approach from D-glucose. ${ }^{208}$

Starting from that promising result, Pinto and coworkers argues that the protonation of the nitrogen atom in the active site provides electrostatic stabilization with carboxylate residues. They reasoned that (i) the permanent positive charge on the sulfonium or the selenium ions would serve to mimic this interaction, and (ii) an erythritol side chain containing an internal sulfate counterion would be advantageous in stabilizing the compound, as in the case of the biologically important
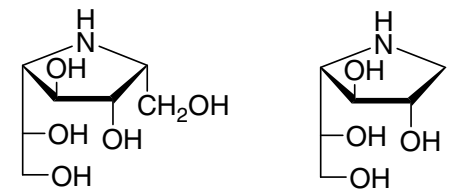

Figure 20. Imino-sugars analogues of UDP-Galf.
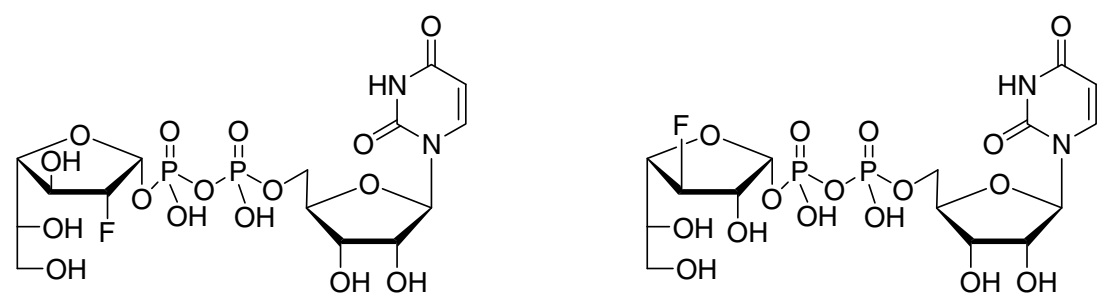

Figure 18. Fluorinated analogues of UDP-Galf.
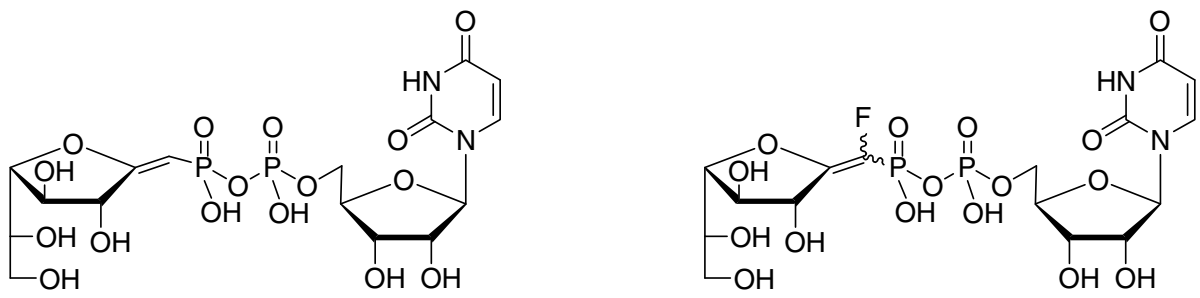

Figure 19. exo-glycal analogues and fluorinated exo-glycals analogues of UDP-Galf. 

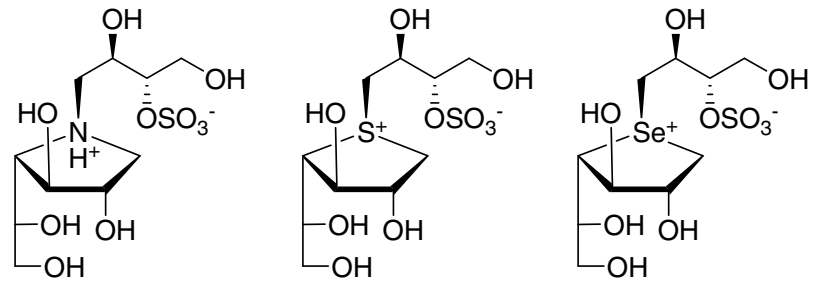

Figure 21. Ammonium, sulfonium and selenium ions as inhibitors of UDP-Galf.

salacinol. ${ }^{209,210}$ Consequently, they prepared a series of ammonium, sulfonium and selenium salts analogs of galactofuranose (Fig. 21). ${ }^{211,212}$ Unfortunately all of them proved to be very poor inhibitors of the mutase since concentrations of at least $10 \mathrm{mM}$ were required.

An explanation for this failure, as proposed by the authors, relies on the presence of a tryptophan residue located in the putative active site cleft that could interact with UDP. Since these compounds were lacking that part, a promising way to enhance such structures will be to add nucleotide moieties. A similar strategy was recently reported by Liautard et al. resulting in $C$-iminosugar analogues (Fig. 22) via the 1,3-dipolar cycloaddition of a uridine derivative carrying an allylphosphono group and a galactofuranose-derived cyclic nitrone. ${ }^{213,214}$ These novel potential sugar nucleotide mimics are actually under biological investigation.

4.1.2. Inhibitors of hydrolases. Thioglycosides are generally resistant to acidic and enzymatic hydrolysis. Their structure closely resembles that of the natural substrate. Therefore they represent a particular class of inhibitors of glycosidase and they have often been used for Xray investigation of the structure of the enzyme-substrate complex. In addition, they can also be used as glycosyl donors in the convergent synthesis of oligosaccharides (see above).

De Lederkremmer and Marino applied this concept in order to inhibit galactofuranosidases, an important target for the discovery of new drugs. ${ }^{215,216}$ The thiogalactofuranosides (Fig. 23) were easily obtained in good yields (generally higher than $85 \%$ ) by S-glycosylation of penta- $O$-benzoyl-galactofuranose in the presence of
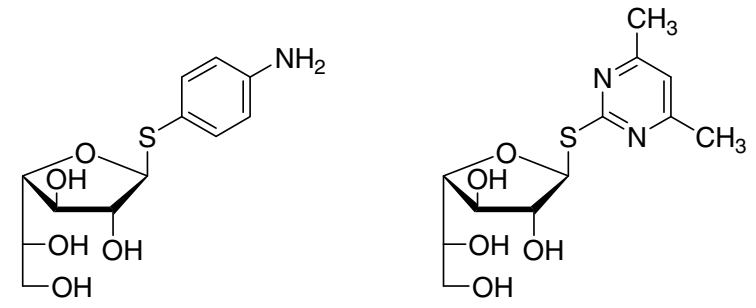

Figure 23. Inhibitors of exo- $\beta$-D-galactofuranosidase from Penicillium fellutanum.

$\mathrm{SnCl}_{4}$ or $\mathrm{BF}_{3} . \mathrm{Et}_{2} \mathrm{O}$ as catalyst, followed by O-deacetylation with sodium methoxide. The compounds demonstrated moderate to good $\mathrm{IC}_{50}$ values up to $80 \mu \mathrm{M}$.

Moreover, de Lederkremer and Alves have extended the biological application's field of such inhibitors and cleverly immobilized 4-aminophenyl 1-thio- $\beta$-D-galactofuranoside on $\mathrm{CH}$-Sepharose $4 \mathrm{~B}$ in order to form a matrix for affinity purification of exo- $\beta$-D-galactofuranosidase. ${ }^{3}$ Following that example, we have recently synthesized a series of thioimidoyl furanosides as inhibitors of the $\alpha$-L-arabinofuranosidase AbfD $3{ }^{217}$ This particular enzyme is able to degrade the biomass and has also been used as an efficient biocatalyst to prepare natural and non-natural disaccharides. ${ }^{195,218,246}$ Moreover, it has been shown recently that the lack of activity of the $\alpha$-L-arabinofuranosidase XYL3 resulted in the decrease of seed size and a delayed germination without affecting the seed viability. ${ }^{219}$ Despite the fact that our best thiogalactofuranoside derivative proved to be a very weak inhibitor (Fig. 24), it helped us in designing the thiazol-2-yl thioarabinofuranoside, which demonstrated a good inhibition constant of $1.2 \mu \mathrm{M}$.
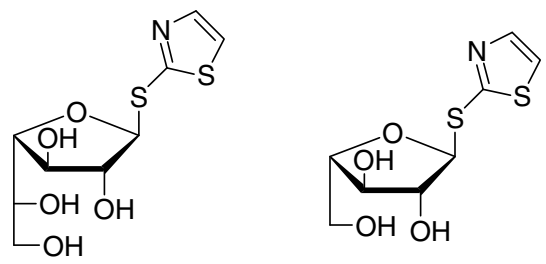

Figure 24. Inhibitors of the $\alpha$-L-arabinofuranosidase AbfD3 from Thermobacillus xylanyliticus.

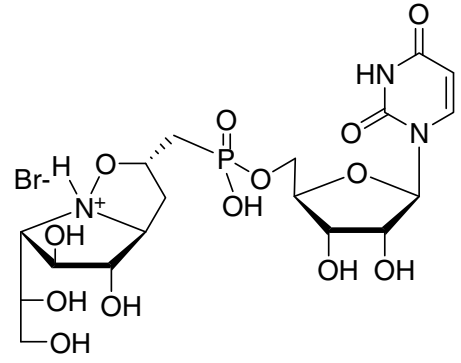

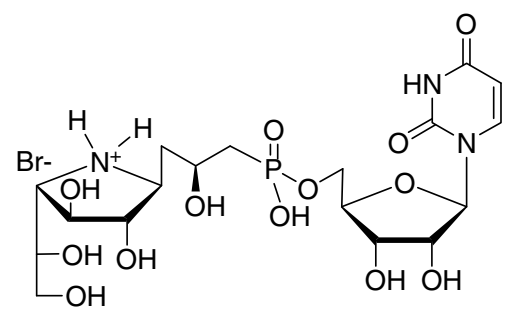

Figure 22. Imino-sugars as new mimics of UDP-Galf. 

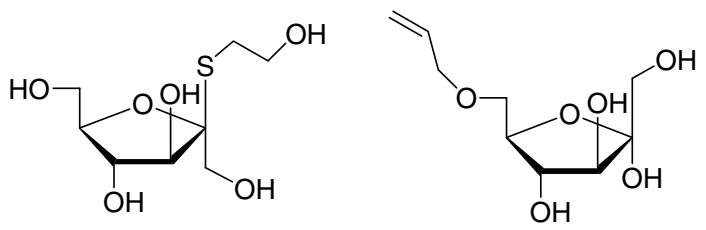

Figure 25. Enzyme inhibitors from fructofuranosides.

D-Fructose is another interesting potential source of hexofuranosyl compounds since it represents the second most abundant simple sugar in nature and so is a significant component of human dietary sugar intake. Two recent examples of inhibitors of enzymes of the fructose metabolism can be found in the literature (Fig. 25). The first one is based on a simple thiofructofuranoside which proved to be a very efficient inhibitor of $\beta$-D-fructofuranosidase and also rat intestinal sucrase. ${ }^{220}$ The second compound, 6- $O$-allyl-D-fructose, obtained in more than $20 \%$ overall yield from methyl D-fructofuranoside, has also demonstrated some activity on the mammalian sodium independent transporter of $\mathrm{D}$-fructose named GLUT5, with a $K_{\mathrm{i}}$ of $20.3 \mathrm{mM} .^{221}$

4.1.3. Antimycobacterial agents. Key structural components of the mycobacterial cell wall are arabinogalactan and lipoarabinomannan. Both are known to be essential to the viability of the organisms and to be responsible for impermeability of the cell wall to many antibacterial drugs. Although considerable efforts have been made for developing inhibitors targeting this biosynthetic pathway, there are few based on the Gal $f$ structure that demonstrated significant activity. Promising leads lie in the $N, N$-dialkyl sulfenamide and sulfonamide derivatives as well as their $S-C$ isosteres recently described by von Itztein and co-workers (Fig. 26). ${ }^{22,223}$ All of them showed in vitro inhibition of mycobacterial growth with MIC below $5 \mu \mathrm{g} / \mathrm{mL}$.

Apart from that strategy, Centrone and Lowary have recently reported the synthesis of six $C$-phosphonate analogues of decaprenolphosphoarabinofuranose (Fig. 27) as inhibitors mimicking the donor substrate of arabinofuranosyltransferases responsible for the biosynthesis of such glycopolymers. ${ }^{24}$ Among them, one revealed an interesting MIC of $3.13 \mu \mathrm{g} / \mathrm{mL}$.
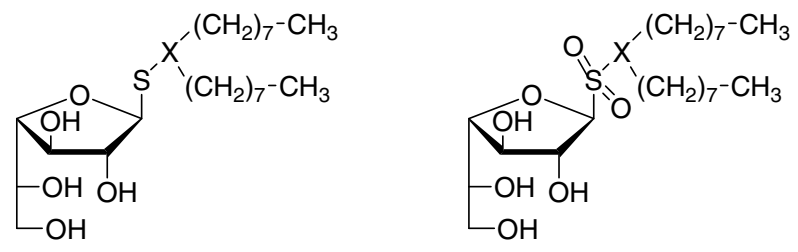

$\mathrm{X}=\mathrm{N}$ or $\mathrm{CH}$

Figure 26. Examples of galactofuranosyl dialkyl sulfenamide and sulfonamide as antimycobacterial agents.

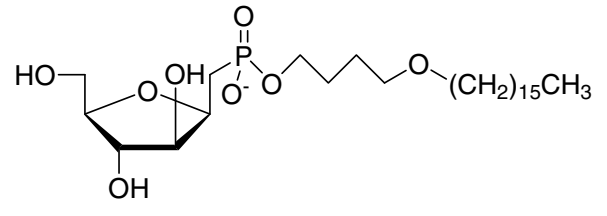

Figure 27. $C$-Phosphonate analogue of decaprenolphosphoarabinose as antimycobacterial agents.

4.1.4. Cancer therapy. Agelagalastatin (Fig. 13) is a natural glycosphingolipid isolated from Agelas sp. ${ }^{54}$ and its total synthesis has been described recently. ${ }^{183} \mathrm{Be}-$ sides its unique structure, this compound displayed significant in vitro inhibitory activities against human cancer cell growth with GI50 values ranging from $0.77 \mu \mathrm{g} / \mathrm{mL}$ for lung NCI-H460 to $2.8 \mu \mathrm{g} / \mathrm{mL}$ for the ovarian OVCAR-3. Another interesting example of hexofuranoside showing antitumour activity on various cell lines has been published by Dominguez et al. ${ }^{225}$ This compound (Fig. 28) is a synthetic $C$-glycosyl analog of $\mathrm{D}$-mannose, obtained in $71 \%$ yield by the reaction between a dithioester and 1,12-dodecyldiamine.

\subsection{Chemistry}

In addition to the important biological applications of such hexofuranoside derivatives, and keeping aside their utilization as glycosyl donors or chiral pool, they have also been used in the field of chemistry for various applications. Perhaps the most ingenious one has been developed by Kobayashi in 1997 known as the "fucofuranoside method".226 This technique allowed the determination of the absolute configuration of secondary alcohols as well as tertiary ones substituted with methyl and two methylene groups, ${ }^{227}$ simply by derivatizing them to a 1:1 mixture of $\beta$-D- and $\beta$-L-fucofuranosides

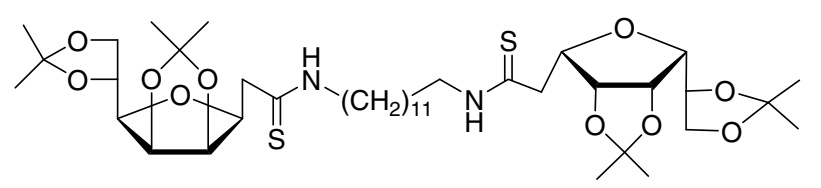

Figure 28. 2- $C$-(2,3:5,6-di- $O$-isopropylidene)- $\beta$-D-mannofuranosyldithioacetate derivative.

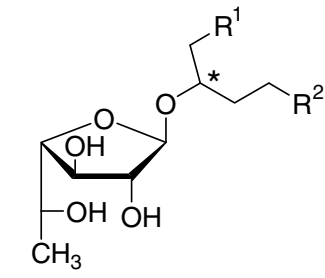

$\beta$-D-fucofuranoside

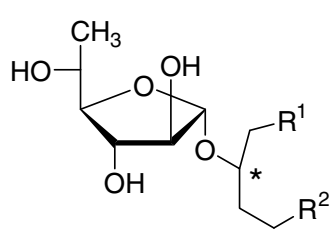

$\beta$-L-fucofuranoside
Figure 29. The fucofuranoside method. 
(Fig. 29) and analyzing their ${ }^{1} \mathrm{H}$ or ${ }^{13} \mathrm{C}$ NMR spectra. Following this method, if the secondary alcohol is of (S)-type, then the difference between the ${ }^{13} \mathrm{C}$ chemical shift values of the anomeric carbon, $\alpha$-carbon and the left-hand $\beta$-carbon is significant and negative, but it is small for the right-hand $\beta$-carbon. If the alcohol is of $(R)$-type, the difference follows a similar scheme (inverting the role of the left-hand and the right-hand $\beta$-carbon) but with positive values. This was exemplified during the determination of the absolute stereochemistry of lupine triterpenoids ${ }^{36}$ and completed by the arabinofuranoside method. ${ }^{228}$

Inorganic chemistry is another field of application for hexofuranosides. It is noteworthy that pentacoordinate phosphorus is considered to be an intermediate or transition state in the formation or in the hydrolysis of biologically relevant phosphorus compounds such as DNA, RNA and c-AMP. Thus modelling active site interactions of phosphoryl transfer enzymes and obtaining solid-state structural information are of utmost interest. Holmes group is among the major actors of this domain and his team has recently prepared and solved the X-ray structures of several biologically relevant phosphoranes based on glucofuranose and xylofuranose..$^{229-231}$ One example is represented in Figure 30.

Finally, the most promising way of using hexofuranosides lies in catalysis. ${ }^{232}$ Asymmetric catalysis is usually a strategy where a transition metal complex containing a chiral ligand catalyses the transformation of a prochiral substrate into one enantiomer as a major product. From this simple definition the design of the chiral ligand appears to be a crucial step and carbohydrates are a natural and cheap source of compounds owing with several stereogenic centres. This major topic has recently been reviewed by Diéguez et al. ${ }^{232}$ and, therefore, only two samples of chiral ligands based on the hexofuranose framework are shown in Figure 31.

\subsection{Physicochemical applications}

Interest for carbohydrates and their potential applications in materials has recently raised due to their

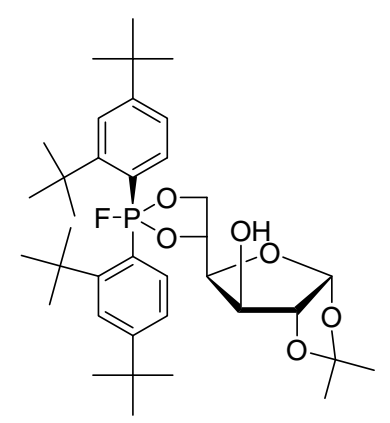

Figure 30. Example of a biologically relevant phosphorane.

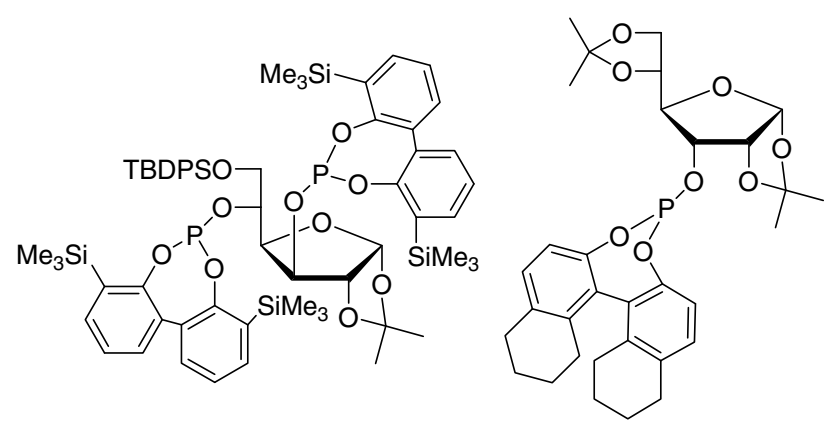

Figure 31. Examples of chiral hexofuranose-based ligands used in asymmetric catalysis.

high potency for hydrogen-bondings and because they are likely to be biocompatible and biodegradable. Hexofuranosides are in no way excluded from that research.

4.3.1. Amphiphiles and gelators. Lipids of thermophilic and thermoacidic Archaebacteria are characterized by tetraether-type macrocylic components bearing one or two polar headgroups derived from phosphate and/or sugar moieties (even hexofuranoses) at the terminal ends of a lipidic backbone. ${ }^{151}$ These latter fit well in the class of bolaamphiphiles, which consists in molecules possessing two polar headgroups connected to each other through one or more hydrophobic spacers. These macrocyclic molecular components are of utmost interest as they are able to form advanced liposomes and artificial membranes with advantageous properties like mechanical, chemical and enzymatic stability for instance. Therefore they represent good candidates for biotechnological applications such as fertilization, drug or antigen delivery and membrane proteine/peptide reconstitution. However, obtaining sufficient amounts of chemically pure material from natural sources still remains difficult. Thus, for more than 10 years now, Benvegnu, Plusquellec and co-workers have developed the synthesis of symmetrical and unsymmetrical analogues of such derivatives (Fig. 32) and studied their physical properties. ${ }^{233-239}$ Among them, some compounds with the capacity to self-assemble into monolayer systems are currently under investigation for the encapsulation and the delivery of biomaterials.

In recent years the development of new gelators of organic fluids as well as the investigation of gelating process and gel structures has received much attention. The gelators can be classified into two categories according to the difference in the driving force for the molecular aggregation: non-hydrogen-bond-based gelators or hydrogen-bond-based gelators. Saccharides, having free $\mathrm{OH}$ groups, fall within the latter group. Once again, Dglucofuranose ketal derivatives under different monoacetal forms (Fig. 33), demonstrated high gelating ability 


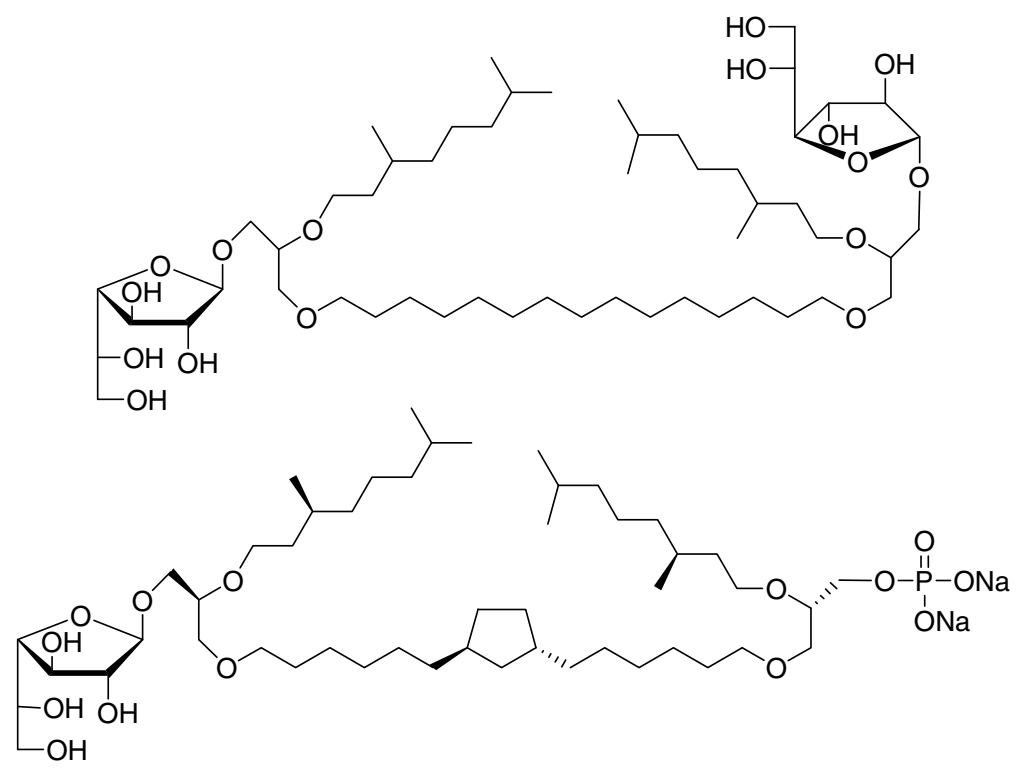

Figure 32. Synthetic symmetrical and unsymmetrical analogues of natural archaeal glycolipids.

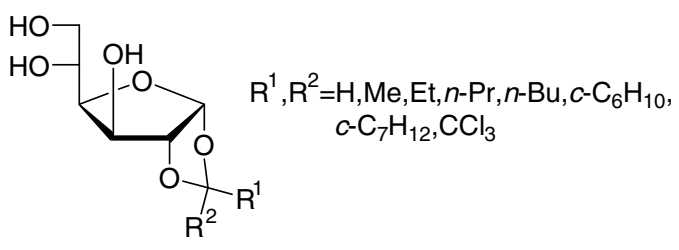

Figure 33. D-Glucofuranose structures of some small organic gelators.

in numerous classical organic solvents (toluene, chloroform, cyclohexane, etc.) at a concentration sometimes lower than $30 \mathrm{mg} / \mathrm{mL}{ }^{240-242}$ Interestingly, its C-3 epimer D-allofuranose exhibited very poor ability to form gels, probably due to a different network of hydrogenbondings as shown by their crystal structure.

The design of small molecules able to gel water still remains a challenge. They represent attractive targets since it is sometimes possible to delineate various factors at the molecular level that are responsible for gelation in preference to crystallization, solubilization, or precipitation. The tetrameric sugar-based azobenzene (Fig. 34) showed pronounced gelation ability of water from $\mathrm{pH}$ 4 to 10 and even in the presence of different salts in aqeous media. ${ }^{243}$ This process notably involved hydrogenbondings through sugar moieties and $\pi-\pi$ stacking of the benzene rings. Unfortunately none of the closely-related hexofuranose analogues synthesized showed hydrogelation properties.

4.3.2. Dendrimers. However, these hexofuranose analogues designed previously have served as scaffolds for a new glycodendrimer (Fig. 35). ${ }^{244}$ It is noteworthy that

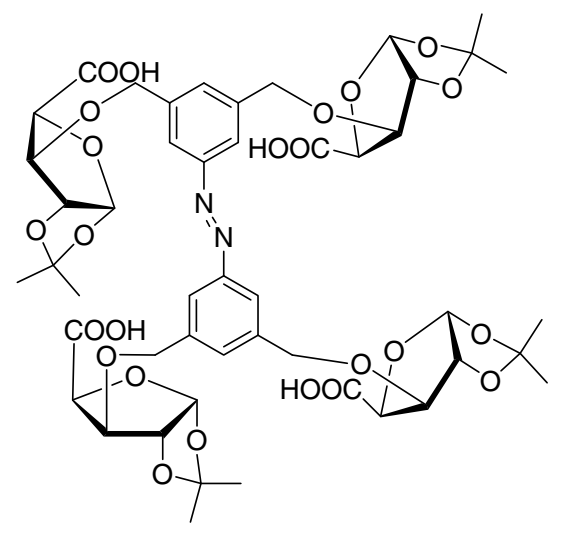

Figure 34. Chemical structure of an efficient hydrogelator based on azobenzene core and a pentofuranose.

this new structure bears an azobenzene stem with easy cis-trans isomerization property which may be useful for the construction of photoswitchable devices.

4.3.3. New biopolymers. Finally, the preparation of hyperbranched polysaccharides Poly-1 and Poly-2 has been achieved by ring-opening multibranching polymerization of 1,6-anhydro-D-glucopyranose and 1,6-anhydro-D-galactopyranose using a thermally induced cationic initiator (Fig. 36). ${ }^{245}$ NMR analysis revealed 17 kinds of repeating units for Poly- 1 and 23 kinds for Poly-2, among which an important proportion of hexofuranosides has been described. Their structures proved to be spherical and the low intrinsic viscosity as well as the lack of entanglement should allow the use of such polymers as biocompatible and biodegradable viscosity modifiers. 


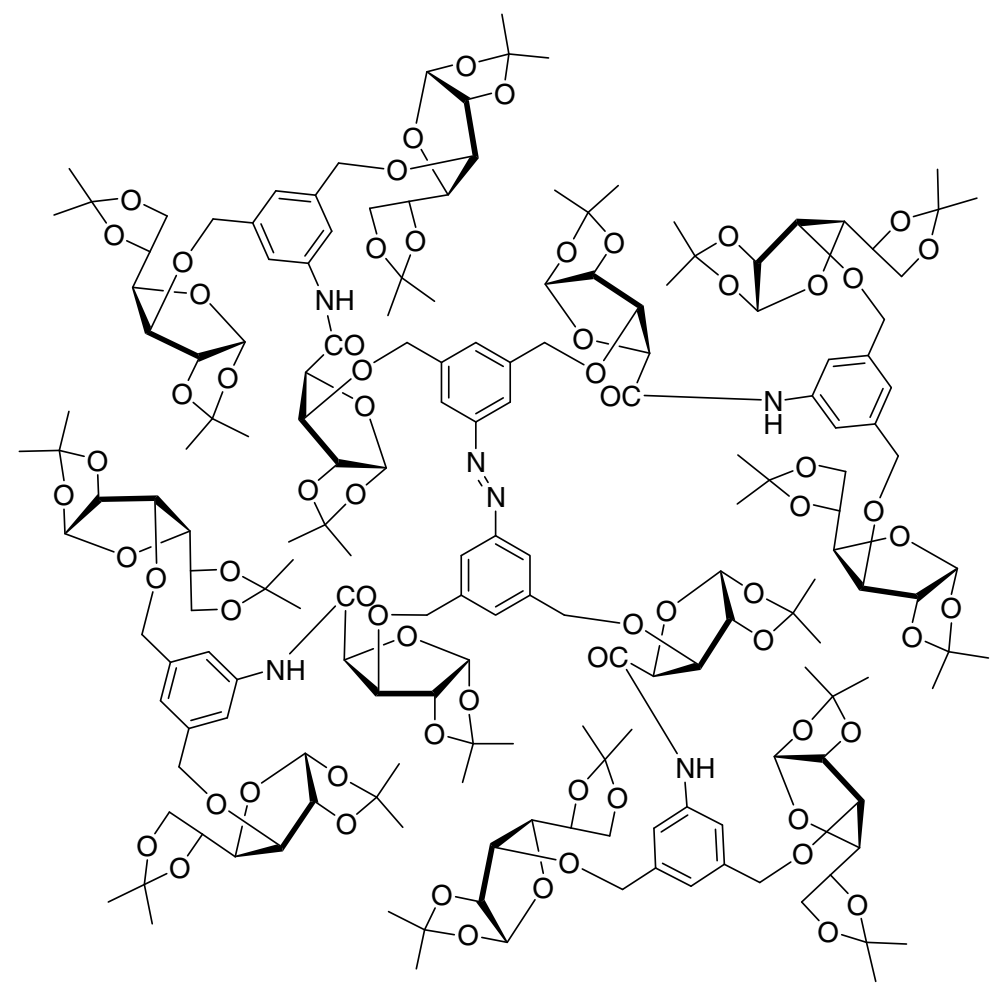

Figure 35. A glycodendrimer.

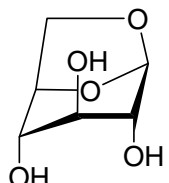

or

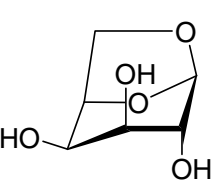

Poly-1 or Poly-2

$\Delta$
Figure 36. Synthesis of hyperbranched D-glucan and D-galactan.

\section{Acknowledgements}

P.P. and R.E. are grateful to the Région Bretagne and the Ministère de l'Education Nationale et de la Recherche, respectively, for grants.

\section{References}

1. Holemann, A.; Seeberger, P. H. Curr. Opin. Biotechnol. 2004, 15, 615-622.

2. Lowary, T. L. Curr. Opin. Chem. Biol. 2003, 7, 749-756.

3. Miletti, L. C.; Marino, C.; Marino, K.; de Lederkremer, R. M.; Colli, W.; Alves, M. J. M. Carbohydr. Res. 1999, 320, 176-182.

4. Rose, N. L.; Completo, G. C.; Lin, S. J.; McNeil, M.; Palcic, M. M.; Lowary, T. L. J. Am. Chem. Soc. 2006, 128, 6721-6729.
5. Wing, C.; Errey, J. C.; Mukhopadhyay, B.; Blanchard, J. S.; Field, R. A. Org. Biomol. Chem. 2006, 4, 3945-3950.

6. Chad, J. M.; Sarathy, K. P.; Gruber, T. D.; Addala, E.; Kiessling, L. L.; Sanders, D. A. R. Biochemistry 2007, 46, 6723-6732.

7. Kleczka, B.; Lamerz, A.-C.; van Zandbergen, G.; Wenzel, A.; Gerardy-Schahn, R.; Wiese, M.; Routier, F. H. J. Biol. Chem. 2007, 282, 10498-10505.

8. Collins, P.; Ferrier, R. Monosaccharides. Their Chemistry and their Roles in Natural Products; John Wiley and Sons Ltd, 1995, pp 4-57.

9. Thibaudeau, C.; Foldesi, A.; Chattopadhyaya, J. Tetrahedron 1998, 54, 1867-1900.

10. Luyten, I.; Thibaudeau, C.; Chattopadhyaya, J. J. Org. Chem. 1997, 62, 8800-8808.

11. Plavec, J.; Tong, W.; Chattopadhyaya, J. J. Am. Chem. Soc. 1993, 115, 9734-9746.

12. Houseknecht, J. B.; Lowary, T. L. Curr. Opin. Chem. Biol. 2001, 5, 677-682.

13. Callam, C. S.; Gadikota, R. R.; Krein, D. M.; Lowary, T. L. J. Am. Chem. Soc. 2003, 125, 13112-13119.

14. Houseknecht, J. B.; Lowary, T. L. J. Org. Chem. 2002, 67, 4150-4164.

15. Houseknecht, J. B.; McCarren, P. R.; Lowary, T. L.; Hadad, C. M. J. Am. Chem. Soc. 2001, 123, 8811-8824.

16. Brennan, P. J.; Nikaido, H. Annu. Rev. Biochem. 1995, 64, 29-63.

17. Pedersen, L. L.; Turco, S. J. Cell. Mol. Life Sci. 2003, 60, 259-266.

18. de Lederkremer, R. M.; Colli, W. Glycobiology 1995, 5, 547-552.

19. Kamphuis, H. J.; Notermans, S.; Veeneman, G. H.; van Boom, J. H.; Rombouts, F. M. In Fungal Cell Wall and Immune Response, Latgé, J. P.; Boucias, D.; NATO ASI Series, 1991; H53, pp. 157-167. 
20. Tungland, B. C. ACS Symp. Ser. 2003, 849, 135-152.

21. Gambacorta, A.; Gliozzi, A.; De Rosa, M. World J. Microbiol. Biotechnol. 1995, 11, 115-131.

22. Leal, J. A.; Gómez-Miranda, B.; Prieto, A.; Domenech, J.; Ahrazm, O.; Bernabé, M. Mycol. Res. 1997, 101, 1259-1264.

23. Prieto, A.; Bernabé, M.; Leal, J. A. Mycol. Res. 1995, 99, 69-75.

24. Leal, J. A.; Prieto, A.; Ahrazm, O.; Pereyra, M.-T.; Bernabé, M. Recent Res. Dev. Microbiol. 2001, 5, 235248.

25. Jones, C.; Todeschini, A. R.; Agrellos, O. A.; Previato, J. O.; Mendonça-Previato, L. Biochemistry 2004, 43, 11889-11897.

26. Domenech, J.; Prieto, A.; Barasoain, I.; Gómez-Miranda, B.; Bernabé, M.; Leal, J. A. Microbiology 1999, 145, 2789-2796.

27. Molinaro, A.; Piscopo, V.; Lanzetta, R.; Parrilli, M. Carbohydr. Res. 2002, 337, 1707-1713.

28. Prieto, A.; Leal, J. A.; Poveda, A.; Jimenéz-Barbero, J.; Gómez-Miranda, B.; Domenech, J.; Ahrazem, O.; Bernabé, M. Carbohydr. Res. 1997, 304, 281-291.

29. Leal, J. A.; Jimenéz-Barbero, J.; Gómez-Miranda, B.; Prieto, A.; Domenech, J.; Bernabé, M. Carbohydr. Res. 1996, 283, 215-222.

30. Bernabé, M.; Ahrazm, O.; Prieto, A.; Leal, J. A. Electron. J. Environ. Agric. Food Chem. 2002.

31. Leitao, E. A.; Bittencourt, V. C. B.; Haido, R. M. T.; Valente, A. P.; Peter-Katalinic, J.; Letzel, M.; de Souza, L. M.; Barreto-Bergter, E. Glycobiology 2003, 13, 681692.

32. Sorum, U.; Robertsen, B.; Kenne, L. Carbohydr. Res. 1998, 306, 305-314.

33. Latge, J. P.; Kobayashi, H.; Debeaupuis, J. P.; Diaquin, M.; Sarfati, J.; Wieruszeski, J. M.; Parra, E.; Bouchara, J. P.; Fournet, B. Infect. Immun. 1994, 62, 5424-5433.

34. de Lederkremer, R. M.; Lima, C.; Ramirez, M. I.; Ferguson, M. A.; Homans, S. W.; Thomas-Oates, J. J. Biol. Chem. 1991, 266, 23670-23675.

35. McConville, M. J.; Homans, S. W.; Thomas-Oates, J. E.; Dell, A.; Bacic, A. J. Biol. Chem. 1990, 265, 7385-7394.

36. Perry, M. B.; MacLean, L. L. Carbohydr. Res. 2004, 339, 1399-1402.

37. Leitão, E. A.; Bittencourt, V. C. B.; Haido, R. M. T.; Valente, A. P.; Peter-Katalinic, J.; Letzel, M.; de Souza, L. M.; Barreto-Bergter, E. Glycobiology 2003, 13, 681692.

38. Leal, J. A.; Guerrero, C.; Gómez-Miranda, B.; Prieto, A.; Bernabé, M. FEMS Microbiol. Lett. 1992, 90, 165-168.

39. Leal, J. A.; Jimenéz-Barbero, J.; Gómez-Miranda, B. Carbohydr. Res. 1995, 273, 255-262.

40. Barreto-Bergter, E.; Gorin, P. A. J.; Travassos, L. R. Carbohydr. Res. 1981, 95, 205-218.

41. Leal, J. A.; Prieto, A.; Gómez-Miranda, B.; JimenézBarbero, J.; Bernabé, M. Carbohydr. Res. 1993, 244, 361368.

42. Besra, G. S.; Khoo, K.-H.; McNeil, M. R.; Dell, A.; Morris, H. R.; Brennan, P. J. Biochemistry 1995, 34, 4257-4266.

43. McNeil, M. R.; Daffé, M.; Brennan, P. J. J. Biol. Chem. 1990, 265, 18200-18206.

44. Daffé, M.; Brennan, P. J.; McNeil, M. R. J. Biol. Chem. 1990, 265, 6734-6743.

45. McNeil, M. R.; Daffé, M.; Brennan, P. J. J. Biol. Chem. 1991, 266, 13217-13223.

46. Ahrazem, O.; Prieto, A.; Gómez-Miranda, B.; Bernabé, M.; Leal, J. A. Microbiology 2001, 147, 1839-1849.
47. Parra, E.; Jimenéz-Barbero, J.; Bernabé, M.; Leal, J. A.; Prieto, A.; Gómez-Miranda, B. Carbohydr. Res. 1994, 257, 239-248.

48. Parra, E.; Jiménez-Barbero, J.; Bernabé, M.; Leal, J. A.; Prieto, A.; Gomez-Miranda, B. Carbohydr. Res. 1994, 251, 315-325.

49. Barreto-Bergter, E.; Gorin, P. A. J.; Travassos, L. R. Carbohydr. Res. 1980, 86, 273-285.

50. Levery, S. B.; Toledo, M. S.; Suzuki, E.; Salyan, M. E. K.; Hakomori, S.-i.; Straus, A. H.; Takahashi, H. K. Biochem. Biophys. Res. Commun. 1996, 222, 639-645.

51. Carbonero, E. R.; Cordeiro, L. M. C.; Mellinger, C. G.; Sassaki, G. L.; Stocker-Wörgötter, E.; Gorin, P. A. J.; Iacomini, M. Carbohydr. Res. 2005, 340, 1699-1705.

52. Germond, J.-E.; Delley, M.; D’Amico, N.; Vincent, S. J. F. Eur. J. Biochem. 2001, 268, 5149-5156.

53. Stevenson, G.; Neal, B.; Liu, D.; Hobbs, M.; Packer, N. H.; Batley, M.; Redmond, J. W.; Lindquist, L.; Reeves, P. J. Bacteriol. 1994, 176, 41444156.

54. Pettit, G. R.; Xu, J.-P.; Gingrich, D. E.; Williams, M. D.; Doubek, D. L.; Chapuis, J.-C.; Schmidt, J. M. Chem. Commun. 1999, 915-916.

55. Cafieri, F.; Fattorusso, E.; Mahajna, Y.; Mangoni, A. Liebigs Ann. Chem. 1994, 1187-1189.

56. Gerwig, G. J.; Kamerling, J. P.; Vliegenthart, J. F. G.; Morag, E.; Lamed, R.; Bayer, E. A. Eur. J. Biochem. 1992, 205, 799-808.

57. Vinogradov, E.; Egbosimba, E. E.; Perry, M. B.; Lam, J. S.; Forsberg, C. W. Eur. J. Biochem. 2001, 268, 35663576.

58. Tzianabos, A.; Wang, J. Y.; Kasper, D. L. Carbohydr. Res. 2003, 338, 2531-2538.

59. Eserstam, R.; Rajaguru, T. P.; Jansson, P.-E.; Weintraub, A.; Albert, M. J. Eur. J. Biochem. 2002, 269, 32893295 .

60. Linnerborg, M.; Weintraub, A.; Widmalm, G. Eur. J. Biochem. 1999, 266, 460-466.

61. Czaja, J.; Jachymek, W.; Niedziela, T.; Lugowski, C.; Aldova, E.; Kenne, L. Eur. J. Biochem. 2000, 267, 16721679.

62. Ahrazem, O.; Prieto, A.; Leal, J. A.; Gómez-Miranda, B.; Domenech, J.; Jiménez-Barbero, J.; Bernabé, M. Carbohydr. Res. 1997, 303, 67-72.

63. Jikibara, T.; Takegawa, K.; Iwahara, S. J. Biochem. 1992, 111, 236-243.

64. Ahrazem, O.; Gomez-Miranda, B.; Prieto, A.; Barasoain, I.; Bernabe, M.; Leal, J. A. Mycol. Res. 2000, 104, 603610 .

65. Ahrazem, O.; Gómez-Miranda, B.; Prieto, A.; Bernabé, M.; Leal, J. A. Arch. Microbiol. 2000, 173, 296-302.

66. Sørum, U.; Robertsen, B.; Kenne, L. Carbohydr. Res. 1998, 306, 305-314.

67. Parra, E.; Jimenéz-Barbero, J.; Bernabé, M.; Leal, J. A.; Prieto, A.; Gómez-Miranda, B. Carbohydr. Res. 1994, 251, 315-325.

68. Zdorovenko, E. L.; Varbanets, L. D.; Zatonsky, G. V.; Ostapchuk, A. N. Carbohydr. Res. 2004, 339, 18091812.

69. Bloom, B. R.; Murray, C. J. Science 1992, 257, 10551064.

70. Besra, G. S.; Khoo, K. H.; McNeil, M. R.; Dell, A.; Morris, H. R.; Brennan, P. J. Biochemistry 1995, 34, 4257-4266.

71. Lowary, T. L. In Glycoscience I-III; Fraser-Reid, B., Tatsuda, K., Thiem, J., Eds.; Springer: Berlin, Heidelberg, New York, 2001; pp 2005-2080.

72. Barry, C. E. Biochem. Pharmacol. 1997, 54, 1165-1172. 
73. Pan, F.; Jackson, M.; Ma, Y.; McNeil, M. J. Bacteriol. 2001, 183, 3991-3998.

74. Turco, S. J.; Descoteaux, A. Annu. Rev. Microbiol. 1992, 46, 65-94.

75. McConville, M. J.; Ferguson, M. A. J. Biochem. J. 1993, 294, 305-324.

76. Ilg, T.; Handman, E.; Stierhof, Y. D. Biochem. Soc. Trans. 1999, 27, 518-525.

77. Carreira, J. C.; Jones, C.; Wait, R.; Previato, J. O.; Mendonça-Previato, L. Glycoconjugate J. 1996, 13, 955966.

78. $\mathrm{Ng}, \mathrm{K}$; Handman, E.; Bacic, A. Biochem. J. 1996, 317, 247-255.

79. Sacks, D. L.; Modi, G.; Rowton, E.; Spath, G.; Epstein, L.; Turco, S. J. Proc. Natl. Acad. Sci. U.S.A. 2000, 97, 406-411.

80. Ilg, T. Med. Microbiol. Immunol. 2001, 190, 13-17.

81. Xavier Da Silveira, E.; Jones, C.; Wait, R.; Previato, J. O.; Mendonça-Previato, L. Biochem. J. 1998, 329, 665673.

82. Merello, S.; Xavier, M. T.; Parodi, A. J. Mol. Biochem. Parasitol. 1995, 69, 73-79.

83. Latgé, J. P. M.; Kobayashi, H.; Debeaupuis, J. P.; Biaquin, M.; Sarfati, J.; Wieruszeski, J. M.; Parra, E.; Bouchara, J. P.; Fournet, B. Infect. Immun. 1992, 62, 5424-5433.

84. Latgé, J. P. Clin. Microb. Rev. 1999, 12, 310-350.

85. Bennett, J. E.; Bhattacharjee, A. K.; Glaudemans, C. P. J. Mol. Immunol. 1985, 22, 251-254.

86. Notermans, S.; Veeneman, G. H.; Van Zuylen, C. W. E. M.; Hoogerhout, P.; Van Boom, J. H. Mol. Immunol. 1988, 25, 975-979.

87. Tischer, C. A.; Gorin, P. A. J.; De Souza, M. B.; BarretoBergter, E. Carbohydr. Polym. 2002, 49, 225-230.

88. Prieto, A.; Rupérez, A.; Hernàndez-Barranco, A.; Leal, J. A. Carbohydr. Res. 1988, 177, 265-272.

89. Freston, J. F.; Lapid, E.; Gander, J. E. Can. J. Microbiol. 1970, 16, 687-694.

90. Menninck-Kersten, M. A. S. H.; Ruegebrink, D.; Wasei, N.; Melchers, W. J. G.; Verweij, P. E. J. Clin. Microbiol. 2006, 44, 1711-1718.

91. Levery, S. B.; Toledo, M. S.; Straus, A. H.; Takahashi, H. K. Biochemistry 1998, 37, 8764-8775.

92. San-Blas, G.; Prieto, A.; Bernabé, M.; Ahrazem, O.; Moreno, B.; Leal, J. A. Med. Mycol. 2005, 43, 153159.

93. Jann, B.; Shashkov, A. S.; Kochanowski, H.; Jann, K. Carbohydr. Res. 1994, 264, 305-311.

94. Perry, M. B. Biochem. Cell Biol. 1990, 68, 808-810.

95. Kol, O.; Wieruszeski, J. M.; Strecker, G.; Montreuil, J.; Fournet, B.; Zalisz, R.; Smets, P. Carbohydr. Res. 1991, 217, 117-125.

96. Whitfield, C. Trends Microbiol. 1995, 3, 178-185.

97. Clarke, A. J.; Bronner, D.; Keenleyside, W. J.; Severn, W. B.; Richards, J. C.; Whitfield, C. J. Bacteriol. 1995, 177, 5411-5418.

98. Michael, F. S.; Szymanski, C. M.; Li, J.; Chan, K. H.; Khieu, N. H.; Larocque, S.; Wakarchuk, W. W.; Brisson, J.-R.; Monteiro, M. A. Eur. J. Biochem. 2002, 269, 51195136.

99. Abeygunawardana, C.; Bush, C. A.; Cisar, J. O. Biochemistry 1990, 29, 234-248.

100. Abeygunawardana, C.; Bush, C. A.; Cisar, J. O. Biochemistry 1991, 30, 6528-6540.

101. Bax, A.; Summers, M. F.; Egan, W.; Guirgis, N.; Schneerson, R.; Robbins, J. B.; Ørskov, F.; Ørskov, I.; Vann, W. F. Carbohydr. Res. 1988, 173, 53-64.
102. Roethlisberger, P.; Iida-Tanaka, N.; Hollemeyer, K.; Heinzle, E.; Ishizuka, I.; Fischer, V. Eur. J. Biochem. 2000, 267, 5520-5530.

103. Lipiński, T.; Jones, C.; Lemercinier, X.; KorzeniowskaKowal, A.; Strus, M.; Rybka, J.; Gamian, A.; Piotr, B. H. Carbohydr. Res. 2003, 338, 605-609.

104. Faber, E. J.; van den Haak, M. J.; Kamerling, J. P.; Vliegenthart, J. F. G. Carbohydr. Res. 2001, 331, 173182.

105. Strus, M.; Marewicz, E.; Kukla, G.; Rurańska-Smutnicka, D.; Przondo-Mordarska, A.; Heczko, B. P. Microbiol. Ecol. Health Dis. 2001, 13, 240-245.

106. Yamazaki, K.; Suzuki, M.; Inukai, K.; Kuga, H.; Korenaga, H. Biosci., Biotechnol., Biochem. 1998, 62, 2138-2144.

107. Inoue, K.; Korenaga, H.; Tanaka, N.; Sakamoto, N.; Kadoya, S. Carbohydr. Res. 1988, 181, 135-142.

108. Lindberg, B. Adv. Carbohydr. Chem. Biochem. 1990, 48, 279-318.

109. Fischer, D.; Geyer, A.; Loos, E. FEBS J. 2006, 273, 137149.

110. Fischer, D.; Loos, E.; Geyer, A. Angew. Chem., Int. Ed. 2006, 45, 816-819.

111. Gerwig, G. J.; Kamerling, J. P.; Vliegenthart, J. F. G.; Morag-Morgenstern, E.; Lamed, R.; Bayer, E. A. Eur. J. Biochem. 1991, 196, 115-122.

112. Fedonenko, Y. P.; Zatonsky, G. V.; Konnova, S. A.; Zdorovenko, E. L.; Ignatov, V. V. Carbohydr. Res. 2002, 337, 869-872.

113. Fedonenko, Y. P.; Konnova, O. N.; Zatonsky, G. V.; Shashkov, A. S.; Konnova, S. A.; Zdorovenko, E. L.; Ignatov, V. V.; Knirel, Y. A. Carbohydr. Res. 2004, 339, 1813-1816.

114. Ahrazem, O.; Prieto, A.; Leal, J. A.; Jiménez-Barbero, J.; Bernabé, M. Carbohydr. Res. 2002, 337, 1503-1506.

115. Hatano, K.; Higashide, E.; Shibata, M.; Kameda, Y.; Horri, S.; Mizuno, K. Agric. Biol. Chem. 1980, 44, 11571163.

116. Horri, S.; Fukase, M.; Mizuta, E.; Hatano, K.; Mizuno, K. Chem. Pharm. Bull. 1980, 28, 3601-3611.

117. Nakano, H.; Matsuda, Y.; Ito, K.; Ohkubo, S.; Morimoto, M.; Tomita, F. J. Antibiot. 1981, 34, 266-270.

118. Takahashi, k.; Yoshida, M.; Tomita, F.; Shirahata, K. J. Antibiot. 1981, 34, 271-275.

119. Jain, T. C.; Simolike, G. C.; Jackman, L. M. Tetrahedron 1983, 39, 599-605.

120. Palaniappan, N.; Ayers, S.; Gupta, S.; Habib, E.-S.; Reynolds, K. A. Chem. Biol. 2006, 13, 753-764.

121. Sato, N.; Nakazawa, F.; Ito, T.; Hoshino, T.; Hoshino, E. Carbohydr. Res. 2003, 338, 923-930.

122. Sato, N.; Nakazawa, F.; Sato, M.; Hoshino, E.; Ito, T. Carbohydr. Res. 1993, 245, 105-111.

123. Senchenkova, S. N.; Huang, X.; Laux, P.; Knirel, Y. A.; Shashkov, A. S.; Rudolph, K. Carbohydr. Res. 2002, 337, 1723-1728.

124. Zdorovenko, E. L.; Ovod, V. V.; Zatonsky, G. V.; Shashkov, A. S.; Kocharova, N. A.; Knirel, Y. A. Carbohydr. Res. 2001, 330, 505-510.

125. Hanniffy, O. M.; Shashkov, A. S.; Moran, A. P.; Prendergast, M. M.; Senchenkova, S. y. N.; Knirel, Y. A.; Savage, A. V. Carbohydr. Res. 1999, 319, 124-132.

126. Kerr, A.; Htay, H. Physiol. Plant Pathol. 1974, 4, 3744.

127. Murphy, P. J.; Roberts, W. P. J. Gen. Microbiol. 1979, 114, 207-213.

128. Holmes, B.; Roberts, W. P. J. Appl. Bacteriol. 1981, 50, 443-467. 
129. Lopez, M. M.; Gorris, M. T.; Salcedo, C. I.; Montojo, A. M.; Miro, M. Appl. Environ. Microbiol. 1989, 55, 741746.

130. New, P. B.; Kerr, A. J. Appl. Bacteriol. 1972, 35, 279287.

131. Chaves das Neves, H. J.; Pais, M. S. S. Tetrahedron Lett. 1980, 21, 4387-4390.

132. Park, M. K.; Park, J. H.; Shin, Y. G.; Kim, W. Y.; Lee, J. H.; Kim, K. H. Planta Med. 1996, 62, 363-365.

133. Igarashi, T.; Satake, M.; Yasumoto, T. J. Am. Chem. Soc. 1999, 121, 8499-8511.

134. Sassaki, G. L.; Gorin, P. A. J.; Reis, R. A.; Serrato, R. V.; Elifio, S. L.; Iacomini, M. Carbohydr. Res. 2005, 340, 1808-1817.

135. Mićović, V. M.; Hranisavljević, M.; Miljković-Stojanović, J. Carbohydr. Res. 1969, 10, 525-533.

136. Barrow, K. D.; Collins, J. G.; Rogers, P. L.; Smith, G. M. Eur. J. Biochem. 1984, 145, 173.

137. Gorshkova, R. P.; Kovalchuck, S. V.; Isakov, V. V.; Frolova, G. M.; Ovodov, Y. S. Bioorg. Khim. 1987, 13, 818-824.

138. Hincha, D. K.; Zuther, E.; Hellwege, E. M.; Heyer, A. G. Glycobiology 2002, 12, 103-110.

139. Vijn, I.; Smeekens, S. Plant Physiol. 1999, 120, 351-360.

140. Tramper, J. In Applied Biocatalysis; Cabral, J. M. S., Best, D., Boross, L., Tramper, J., Eds.; Harwood Academic: Switzerland, 1994; pp 1-45.

141. Yun, J. W. Enzyme Microbiol. Technol. 1996, 19, 107117.

142. Ouarne, F.; Guibert, A. Zuckerindustrie 1995, 129, 793.

143. Vandamme, E. J.; Soetaert, W. FEMS Microbiol. Rev. 1995, 163.

144. Yin, H.; Fu, H.; Hua, H.; Pei, Y. Shenyang Yaoke Daxue Xuebao 2006, 23, 641-645.

145. Kotiguda, G.; Peterbauer, T.; Mulimani, V. H. Carbohydr. Res. 2006, 341, 2156-2160.

146. Huang, X.-F.; Luo, J.; Zhang, Y.; Kong, L.-Y. Zhongguo Tianran Yaowu 2006, 4, 181-184.

147. Su, B.-N.; Pawlus, A. D.; Jung, H.-A.; Keller, W. J.; McLaughlin, J. L.; Kinghorn, A. D. J. Nat. Prod. 2005, $68,592-595$

148. Costantino, V.; Fattorusso, E.; Imperatore, E.; Mangoni, A. Eur. J. Org. Chem. 2003, 1433-1437.

149. Miyamoto, T.; Yamamoto, A.; Wakabayashi, M.; Nagaregawa, Y.; Inagaki, M. R. H.; Iha, M.; Teruya, K. Eur. J. Org. Chem. 2000, 2295-2301.

150. Miyamoto, T.; Inagaki, M.; Isobe, R.; Tanaka, N.; Higuchi, M.; Iha, M.; Teruya, K. Liebigs Ann. Chem. 1997, 931-936.

151. Benvegnu, T.; Brard, M.; Plusquellec, D. Curr. Opin. Colloid Interface Sci. 2004, 8, 469-479.

152. D'Accorso, N. B.; Thiel, I. M. E.; Schüller, M. Carbohydr. Res. 1983, 124, 177-184.

153. Furneaux, R. H.; Rendle, P. M.; Sims, I. M. J. Chem. Soc., Perkin Trans. 1 2000, 2011-2014.

154. Ferrières, V.; Bertho, J. N.; Plusquellec, D. Carbohydr. Res. 1998, 311, 25-35.

155. Bertho, J.-N.; Ferrières, V.; Plusquellec, D. Chem. Commun. 1995, 1391-1393.

156. Ferrières, V.; Bertho, J.-N.; Plusquellec, D. Tetrahedron Lett. 1995, 36, 2749-2752.

157. Gelin, M.; Ferrières, V.; Plusquellec, D. Eur. J. Org. Chem. 2000, 1423-1431.

158. Kinzy, W.; Schmidt, R. R. Liebigs Ann. Chem. 1993, 683-690.

159. Velty, R.; Benvengu, T.; Plusquellec, D. Synlett 1996, 9, 817-819.
160. Iga, D. P.; Iga, S.; Schmidt, R. R.; Buzas, M.-C Carbohydr. Res. 2005, 340, 2052-2054.

161. Hederos, M.; Konradsson, P. J. Am. Chem. Soc. 2006, 128, 3414-3419.

162. Ruda, K.; Lindberg, J.; Garegg, P. J.; Oscarson, S.; Konradsson, P. J. Am. Chem. Soc. 2000, 122, 1106711072

163. Pathak, A. K.; Pathak, V.; Seitz, L.; Maddry, J. A.; Gurcha, S. S.; Besra, G. S.; Suling, W. J.; Reynolds, R. C. Bioorg. Med. Chem. 2001, 9, 3129-3143.

164. Arasappan, A.; Fraser-Reid, B. Tetrahedron Lett. 1995, 36, 7967-7970.

165. Zhang, G.; Fu, M.; Ning, J. Carbohydr. Res. 2005, 340, $155-159$

166. Zhang, G.; Fu, M.; Ning, J. Tetrahedron: Asymmetry 2005, 16, 733-738

167. Bohn, M. L.; Colombo, M. I.; Stortz, C. A.; Ruveda, E. A. Carbohydr. Res. 2006, 341, 1096-1104.

168. Ferrières, V.; Joutel, J.; Boulch, R.; Roussel, M.; Toupet, L.; Plusquellec, D. Tetrahedron Lett. 2000, 41, 55155519.

169. Bai, Y.; Lowary, T. L. J. Org. Chem. 2006, 71, 96589671.

170. Ferrières, V.; Blanchard, S.; Fischer, D.; Plusquellec, D. Bioorg. Med. Chem. Lett. 2002, 12, 3515-3518.

171. Euzen, R.; Ferrières, V.; Plusquellec, D. J. Org. Chem. 2005, 70, 847-855.

172. Euzen, R.; Ferrières, V.; Plusquellec, D. Carbohydr. Res. 2006, 341, 2759-2768.

173. Euzen, R.; Guégan, J. P.; Ferrières, V.; Plusquellec, D. J. Org. Chem. 2007, 72, 5743-5747.

174. Smoot, J. T.; Pornsuriyasak, P.; Demchenko, A. V. Angew. Chem., Int. Ed. 2005, 44, 7123-7126.

175. Bai, Y.; Lowary, T. L. J. Org. Chem. 2006, 71, 9672 9680.

176. Fu, M.; Zhang, G.; Ning, J. Carbohydr. Res. 2005, 340, $25-30$.

177. Gandolfi-Donadio, L.; Gallo-Rodriguez, C.; de Lederkremer, R. M. J. Org. Chem. 2003, 68, 6928-6934.

178. Gandolfi-Donadio, L.; Gallo-Rodriguez, C.; de Lederkremer, R. M. J. Org. Chem. 2002, 67, 4430-4435.

179. Wang, H.; Ning, J. J. Org. Chem. 2003, 68, 25212524 .

180. Gelin, M.; Ferrières, V.; Lefeuvre, M.; Plusquellec, D. Eur. J. Org. Chem. 2003, 1285-1293.

181. Cumpstey, I.; Fairbanks, A. J.; Redgrave, A. J. Tetrahedron 2004, 60, 9061-9074.

182. Gadikota, R. R.; Callam, C. S.; Lowary, T. L. Org. Lett. 2001, 3, 607-610.

183. Lee, Y. J.; Lee, B. Y.; Jeon, H. B.; Kim, K. S. Org. Lett. 2006, 8, 3971-3974.

184. Lee, R.; Monsey, D.; Weston, A.; Duncan, K.; Rithner, C.; McNeil, M. Anal. Biochem. 1996, 242, 1-7.

185. Barlow, J. N.; Blanchard, J. S. Carbohydr. Res. 2000 , $328,473-480$.

186. Tsvetkov, Y. E.; Nikolaev, A. V. J. Chem. Soc., Perkin Trans. 1 2000, 889-891.

187. Zhang, Q.; Liu, H.-W. J. Am. Chem. Soc. 2000, 122 , 9065-9070.

188. de Lederkremer, R. M.; Nahmad, V. B.; Varela, O. J. Org. Chem. 1994, 59, 690-692.

189. Marlow, A. L.; Kiessling, L. L. Org. Lett. 2001, 3, $2517-$ 2519.

190. Mariño, K.; Marino, C.; Lima, C.; Baldoni, L.; de Lederkremer, R. M. Eur. J. Org. Chem. 2005, 2958-2964.

191. Ferrières, V. In 14th European Carbohydrate Symposium, Lübeck, Germany, 2007, Abstract IL 001. 
192. Peltier, P.; Daniellou, R.; Nugier-Chauvin, C.; Ferrières, V. Org. Lett. 2007, 9, 5227-5230.

193. Errey, J. C.; Mukhopadhyay, B.; Kartha, K. P. R.; Field, R. A. Chem. Commun. 2004, 2706-2707.

194. Rémond, C.; Plantier-Royon, R.; Aubry, N.; O’Donohue, M. J. Carbohydr. Res. 2005, 340, 637-644.

195. Euzen, R.; Lopez, G.; Nugier-Chauvin, C.; Ferrières, V.; Plusquellec, D.; Rémond, C.; O’Donohue, M. Eur. J. Org. Chem. 2005, 4860-4869.

196. Agusti, R.; Giorgi, M. E.; Mendoza, V. M.; GalloRodriguez, C.; de Lederkremer, R. M. Bioorg. Med. Chem. 2007, 15, 2611-2616.

197. Müllegger, J.; Chen, H. M.; Warren, R. A. J.; Withers, S. G. Angew. Chem., Int. Ed. 2006, 118, 2647-2650.

198. Kremer, L.; Dover, L. G.; Morehouse, C.; Hitchin, P.; Everett, M.; Morris, H. R.; Dell, A.; Brennan, P. J.; McNeil, M.; Flaherty, C.; Duncan, K.; Besra, G. S. J. Biol. Chem. 2001, 276, 25440-26430.

199. Catelani, G.; Osti, F.; Bianchi, N.; Bergonzi, M. C.; D’Andrea, F.; Gambari, R. Bioorg. Med. Chem. Lett. 1999, 9, 3153-3158.

200. Sanders, D. A. R.; McMahon, S. A.; Leonard, G. L.; Naismith, J. H. Acta Crystallogr., Sect. D 2001, 57, 14151420.

201. Beis, K.; Srikannathasan, V.; Liu, H.; Fullerton, S. W. B.; Bamford, V. A.; Sanders, D. A. R.; Whitfield, C.; McNeil, M. R.; Naismith, J. H. J. Mol. Biol. 2005, 348, 971-982.

202. Kovensky, J.; McNeil, M.; Sinay, P. J. Org. Chem. 1999, 64, 6202-6205.

203. Zhang, Q.; Liu, H. W. J. Am. Chem. Soc. 2001, 123, 6756-6766.

204. Caravano, A.; Vincent, S. P.; Sinaÿ, P. Chem. Commun. 2004, 1216-1217.

205. Caravano, A.; Dohi, H.; Sinaÿ, P.; Vincent, S. P. Chem. Eur. J. 2006, 12, 3114-3123.

206. Itoh, K.; Huang, Z.; Liu, H. W. Org. Lett. 2007, 9, 879882.

207. Lee, R. E.; Smith, M. D.; Nash, R. J.; Griffiths, R. C.; McNeil, M.; Grewal, R. K.; Yan, W.; Besra, G. S.; Brennan, P. J.; Fleet, G. W. J. Tetrahedron Lett. 1997, 38, 6733-6736.

208. Pham-Huu, D.-P.; Gizaw, Y.; BeMiller, J. N.; Petrus, L. Tetrahedron 2003, 59, 9413-9417.

209. Ghavami, A.; Johnston, B. D.; Pinto, B. M. J. Org. Chem. 2001, 66, 2312-2317.

210. Mohan, S.; Pinto, B. M. Carbohydr. Res. 2007, 342, $1551-1580$

211. Ghavami, A.; Chen, J. J.-W.; Mario Pinto, B. Carbohydr. Res. 2004, 339, 401-407.

212. Veerapen, N.; Yuan, Y.; Sanders, D. A. R.; Pinto, B. M. Carbohydr. Res. 2004, 339, 2205-2217.

213. Liautard, V.; Christina, A. E.; Desvergnes, V.; Martin, O. R. J. Org. Chem. 2006, 71, 7337-7345.

214. Liautard, V.; Desvergnes, V.; Martin, O. R. Org. Lett. 2006, 8, 1299-1302.

215. Marino, C.; Marino, K.; Miletti, L.; Julia, M.; Alves, M.; Colli, W.; De Lederkremer, R. M. Glycobiology 1998, 8, 901-904.

216. Marino, K.; Marino, C. ARKIVOC 2005, 341-351.

217. Lopez, G.; Daniellou, R.; O’Donohue, M.; Ferrières, V.; Nugier-Chauvin, C. Bioorg. Med. Chem. Lett. 2007, 17, 434-438.

218. Rémond, C.; Plantier-Royon, R.; Aubry, N.; Maes, E.; Bliard, C.; O'Donohue, M. J. Carbohydr. Res. 2004, 339, 2019-2025.
219. Minic, Z.; Do, C.-T.; Rihouey, C.; Morin, H.; Lerouge, P.; Jouanin, L. J. Exp. Bot. 2006, 57, 2339-2351.

220. Kiso, T.; Hamatasu, K.; Fujita, K.; Hara, K.; Kitahata, S.; Nakano, H. Biosci., Biotechnol., Biochem. 2003, 67, 1719-1724.

221. Tatibouët, A.; Yang, J.; Morin, C.; Holman, G. D. Bioorg. Med. Chem. 2000, 8, 1825-1833.

222. Owen, D. J.; Davis, C. B.; Hartnell, R. D.; Madge, P. D.; Thomson, R. J.; Chong, A. K. J.; Coppel, R. L.; von Itzstein, M. Bioorg. Med. Chem. Lett. 2007, 17, 2274 2277.

223. Davis, C. B.; Hartnell, R. D.; Madge, P. D.; Owen, D. J.; Thomson, R. J.; Chong, A. K. J.; Coppel, R. L.; von Itzstein, M. Carbohydr. Res. 2007, 342, 1773-1780.

224. Centrone, C. A.; Lowary, T. L. J. Org. Chem. 2002, 67, 8862-8870.

225. Dominguez, Z. J.; Marchand, P.; Gulea, M.; Masson, S. Carbohydr. Res. 2005, 340, 579-586.

226. Kobayashi, M. Tetrahedron 1997, 53, 5973-5994.

227. Kobayashi, M. Tetrahedron 1998, 54, 10987-10998.

228. Kobayashi, M. Tetrahedron 2002, 58, 9365-9371.

229. Timosheva, N. V.; Chandrasekaran, A.; Holmes, R. R. J. Am. Chem. Soc. 2005, 127, 12474-12475.

230. Timosheva, N. V.; Chandrasekaran, A.; Holmes, R. R. Inorg. Chem. 2006, 45, 10836-10848.

231. Timosheva, N. V.; Chandrasekaran, A.; Holmes, R. R. Inorg. Chem. 2006, 45, 3113-3123.

232. Diéguez, M.; Claver, C.; Pàmies, O. Eur. J. Org. Chem. 2007, 2007, 4621-4634.

233. Auzély-Velty, R.; Benvegnu, T.; Mackenzie, G.; Haley, J. A.; Goodby, J. W.; Plusquellec, D. Carbohydr. Res. 1998, 314, 65-77.

234. Auzély-Velty, R.; Benvegnu, T.; Plusquellec, D.; Mackenzie, G.; Haley, J. A.; Goodby, J. W. Angew. Chem., Int. Ed. 1998, 37, 2511-2515.

235. Lecollinet, G.; Auzély-Velty, R.; Benvegnu, T.; Plusquellec, D.; Lecollinet, G.; Mackenzie, G.; Goodby, J. W. Chem. Commun. 1998, 1571-1572.

236. Lecollinet, G.; Auzély-Velty, R.; Danel, M.; Benvegnu, T.; Mackenzie, G.; Goodby, J. W.; Plusquellec, D. J. Org. Chem. 1999, 64, 3139-3150.

237. Lecollinet, G.; Gulik, A.; Mackenzie, G.; Goodby, J. W.; Benvegnu, T.; Plusquellec, D. Chem. Eur. J. 2002, 8, 585593.

238. Benvegnu, T.; Lecollinet, G.; Guilbot, J.; Roussel, M.; Brard, M.; Plusquellec, D. Polym. Int. 2003, 52, 500 506.

239. Brard, M.; Richter, W.; Benvegnu, T.; Plusquellec, D. J. Am. Chem. Soc. 2004, 126, 10003-10012.

240. Luboradzki, R.; Pakulski, Z. Tetrahedron 2004, 60, 46134616.

241. Luboradzki, R.; Pakulski, Z.; Sartowska, B. Tetrahedron 2005, 61, 10122-10128.

242. Grigoriew, H.; Luboradzki, R.; Gronkowski, J. J. NonCryst. Solids 2006, 352, 3052-3057.

243. Srivastava, A.; Ghorai, S.; Bhattacharjya, A.; Bhattacharya, S. J. Org. Chem. 2005, 70, 6574-6582.

244. Ray, A.; Bhattacharya, S.; Ghorai, S.; Ganguly, T.; Bhattacharjya, A. Tetrahedron Lett. doi:10.1016/ j.tetlet.2007.08.115.

245. Satoh, T.; Imai, T.; Ishihara, H.; Maeda, T.; Kitajyo, Y.; Sakai, Y.; Kaga, H.; Kaneko, N.; Ishii, F.; Kakuchi, T. Macromolecules 2005, 38, 4202-4210.

246. Lopez, G.; Nugier-Chauvin, C.; Remond, C.; O’Donohue, M. Carbohydr. Res. 2007, 342, 2202-2211. 